\title{
Role of specialized pro-resolving lipid mediators in pulmonary inflammation diseases: mechanisms and development
}

\author{
Ailin Yang, Yanjun Wu, Ganggang Yu and Haoyan Wang ${ }^{*}$ (i)
}

\begin{abstract}
Inflammation is an essential mechanism of various diseases. The development and resolution of inflammation are complex immune-modulation processes which induce the involvement of various types of immune cells. Specialized pro-resolving lipid mediators (SPMs) have been demonstrated to be signaling molecules in inflammation. SPMs are involved in the pathophysiology of different diseases, especially respiratory diseases, including asthma, pneumonia, and chronic obstructive pulmonary disease. All of these diseases are related to the inflammatory response and its persistence. Therefore, a deeper understanding of the mechanisms and development of inflammation in respiratory disease, and the roles of the SPM family in the resolution process, might be useful in the quest for novel therapies and preventive measures for pulmonary diseases.
\end{abstract}

Keywords: Inflammation resolution, Lung diseases, Lung inflammation, Pro-resolving lipid mediators, Mechanism

\section{Introduction}

Inflammation is a major defense mechanism of the human body. If the body is subjected to an injury, infection, or other similar stimuli, the innate immune system becomes activated within seconds-to-minutes. Innate immunity is useful in promoting inflammation and can aid in determining the level of pathogenic invasion or stimuli. Although inflammatory reactions evolve as an adaptive reaction that could restore homeostasis, a successful inflammatory response is complete only after resolution and restoration phases $[1,2]$. If inflammation persists or becomes uncontrolled, it could elicit an overprotective response by the body. Thus, inflammatory factors can mediate an auto-immune reaction to attack healthy cells and tissues in the body. This action can cause rheumatoid arthritis, inflammatory bowel disease, psoriasis, asthma, and vasculitis [3, 4]. Recently, studies

\footnotetext{
*Correspondence: gangyu.603@163.com; haoyanw@ccmu.edu.cn Department of Respiratory Medicine, Beijing Friendship Hospital, Capital Medical University, No. 95 Yong An Road, Xicheng, , Beijing 100050, China
}

have shown that chronic, persistent inflammation might be the cause of cancer, neurodegenerative diseases [5] (e.g., Alzheimer's disease, Parkinson disease) and even certain types of mental illness [6].

Acute inflammation is induced by the innate immune system, which has an essential protective role, prevents some infections, and promotes healing in injured tissues. Briefly, if the body is stimulated by inflammation, infection, or other pathogenic factors, an acute immune response is accelerated. Inflammatory cells, such as polymorphonuclear neutrophils (PMNs), macrophages, and dendritic cells (DCs), are recruited by cytokines and chemokines, which accelerate the inflammatory response and reduce further damage to tissues [7].

After the body initially launches an immune response, acute inflammation begins to subside. Phagocytic cells (e.g., macrophages and neutrophils) are mobilized to eliminate apoptotic and necrotic cells and thereby promote the repair/recovery of tissue and maintain tissue homeostasis by generating pro-inflammatory mediators. In health, this process occurs actively in original author(s) and the source, provide a link to the Creative Commons licence, and indicate if changes were made. The images or other third party material in this article are included in the article's Creative Commons licence, unless indicated otherwise in a credit line to the material. If material is not included in the article's Creative Commons licence and your intended use is not permitted by statutory regulation or exceeds the permitted use, you will need to obtain permission directly from the copyright holder. To view a copy of this licence, visit http://creativecommons.org/licenses/by/4.0/. The Creative Commons Public Domain Dedication waiver (http://creativeco mmons.org/publicdomain/zero/1.0/) applies to the data made available in this article, unless otherwise stated in a credit line to the data. 
a specific self-limiting manner. However, if the acute inflammatory response is not controlled or completed within a specific timeframe, inflammation may persist, or the body may initiate an exaggerated inflammatory response, which may lead to inflammation recurrence. Such situations may induce chronic inflammation, disease, or even death [7].

Studies $[8,9]$ have determined that a series of endogenous lipid mediators produced during the resolution of acute inflammation can bind to specific receptors, inhibit neutrophil infiltration, regulate the formation of cytokines and chemokines, and thereby promote extensive phagocytosis. Endogenous lipid mediators, which can eliminate apoptotic cells and necrotic cells and promote tissue repair, can be referred to collectively as "specialized pro-resolving lipid mediators" (SPMs). They include resolvin, protectin, maresins, and lipoxins (LXs), which are converted from omega-6 polyunsaturated fatty acids [10-12]. Animal experiments have demonstrated that SPMs can be involved in the regulation of inflammatory diseases such as arthritis, peritonitis and asthma, as well as ischemia-reperfusion injury and inflammatory pain $[10,13,14]$.

The respiratory system connects the internal and external environment, and can be affected readily by stimuli such as smoke (and other forms of air pollution) and pathogens. The respiratory system also serves as a natural defense system. As various stimuli enter and accumulate in the body's internal environment, they can provoke an inflammatory response in cells and tissues and may even cause a persistent reaction.

A decline in the ability to resolve inflammation fully will cause dysfunction in epithelial cells and alveolar macrophages. This dysfunction constitutes a major mechanism for the persistence of inflammation, as well as further injury to tissues and disruption of normal structure in the pulmonary parenchyma. This dysfunction may even cause asthma, chronic obstructive pulmonary disease (COPD), or pulmonary fibrosis $[3,15]$. Therefore, it is especially important to recognize the relationship between inflammation resolution and the pathogenesis of respiratory diseases.

Recently, studies focusing on the decline in levels of SPMs during the early inflammatory response have demonstrated that these mediators could act as novel targets for the treatment of pulmonary diseases [1618]. Therefore, understanding the mechanism of and resolution of inflammation will aid understanding of the role of SPMs in the early phase of therapy.

In this review, we discuss and update recent research on SPMs in pulmonary inflammation to provide new concepts for the treatment and prognosis of inflammatory disease. In addition, we discuss the SPMs family and their role in the regulation of respiratory diseases.

\section{Inflammation and resolution: mechanism Inflammatory response}

The inflammatory response is a series of immune responses to inflammatory stimuli. A series of complex inflammatory-response mechanisms can protect the human body from the potential harm caused by infection or injury.

If pathogenic bacteria invade and cause damage to cells and tissues, pattern recognition receptors such as toll-like receptors or nod-like receptor expressed by immune cells can recognize pathogenic organisms (pathogen-associated molecular patterns) and damage signals (damageassociated molecular patterns) rapidly and transmit these "danger signals" to the interface of cells and tissues [19]. These signals promote the activation of innate immune cells (neutrophils, macrophages, eosinophils, mast cells, natural killer cells, $\gamma \delta$-T cells, innate lymphoid cells, and $\mathrm{DCs})$, to promote them produce some pro-inflammatory cytokines and chemokines [20, 21]. These chemokines activate the chemotaxis process to recruit leukocytes and macrophages into the site of inflammation center to provide effector functions [22].

Simultaneously, under the influence of vasoactive amines (e.g., histamine) and eicosanoids (e.g., prostaglandins, 5-hydroxyeicosatetraenoic acid), granulocytes and macrophages can up-regulate the expression of complement (C3) and immunoglobulin (Ig) receptors to enhance phagocytosis and cell-killing ability [23]. In addition, inflammation and injury effectively enhancing the immune response and vascular permeability, antibodies and some soluble substances, such as SPMs and its analogs, produced by adaptive immune cells ( $\mathrm{T}$ and B lymphocytes) flow into the center of the inflammatory response with blood plasma to form an acquired immune response. Furthermore, some structural cells in the body, such as airway and alveolar epithelial cells, endothelial cells, and fibroblasts, are also involved in the immune response during the inflammatory response [24]. These structural cells are mainly involved in the production of pro-resolving mediators and adaptive immune responses.

\section{Inflammation resolution}

In health, the body has a complete regulatory mechanism to prevent uncontrolled inflammatory reactions. During activation of the inflammatory response, the influx of inflammatory cells is at its maximum, and the body can secrete a series of pro-resolving mediators (e.g., endogenous lipid-derived mediators) to clear inflammatory cells at the inflammatory center and inhibit PMN infiltration 
to prevent further damage $[18,25]$. As a result, the inflammatory response can be controlled, homeostasis can be regulated, and an excessive inflammatory response and chronic inflammation can be prevented.

The resolution of inflammation is a sophisticated and active process. Its basic processes include: (i) limiting and inhibiting neutrophilic infiltration; (ii) modulating the secretion of chemokines and cytokines; (iii) inducing the apoptosis of neutrophils, and subsequently enhancing the endocytosis and efferocytosis of macrophages [26].

However, regardless of how inflammation is activated and regulated, immune cells will be cleared from tissues. Briefly, during the inflammatory response, many PMNs, eosinophils, or lymphocytes are recruited to the inflammatory center under the induction of chemokines and cytokines, where they are involved in phagocytosis [26]. Thus, these cells become involved in local apoptosis or necrosis. Then monocyte-derived macrophages (MDMs) are also recruited as phagocytes to eliminate these apoptotic and necrotic cells [7]. Macrophages polarization and resolution cascade via the residence cells further produce pro-resolving molecules. Upon completion of exocytosis, macrophages can be removed from the inflammatory site through lymphatic drainage, thereby achieving the subsidence of inflammation. During regression, various complex signaling mechanisms and factors are required to control the balance between processes, including binding of cells to cell receptors and the secretion of endogenous lipid-derived mediators. If the signal-transduction mechanism is abnormal, the system of inflammation regulation will become disrupted, and inflammation will persist. This action will transform acute inflammation into chronic inflammation, which can lead to chronic damage, remodeling, and even fibrosis, and some tissues may lose their functions [27] (Fig. 1).

\section{Post-resolution of inflammation}

Previously, the inflammatory response was thought to comprise two phases: inflammation and resolution. However, recent research $[7,28]$ has revealed that a third phase, known as "post-resolution", can follow inflammation resolution, and thereby affect adaptive immunity and

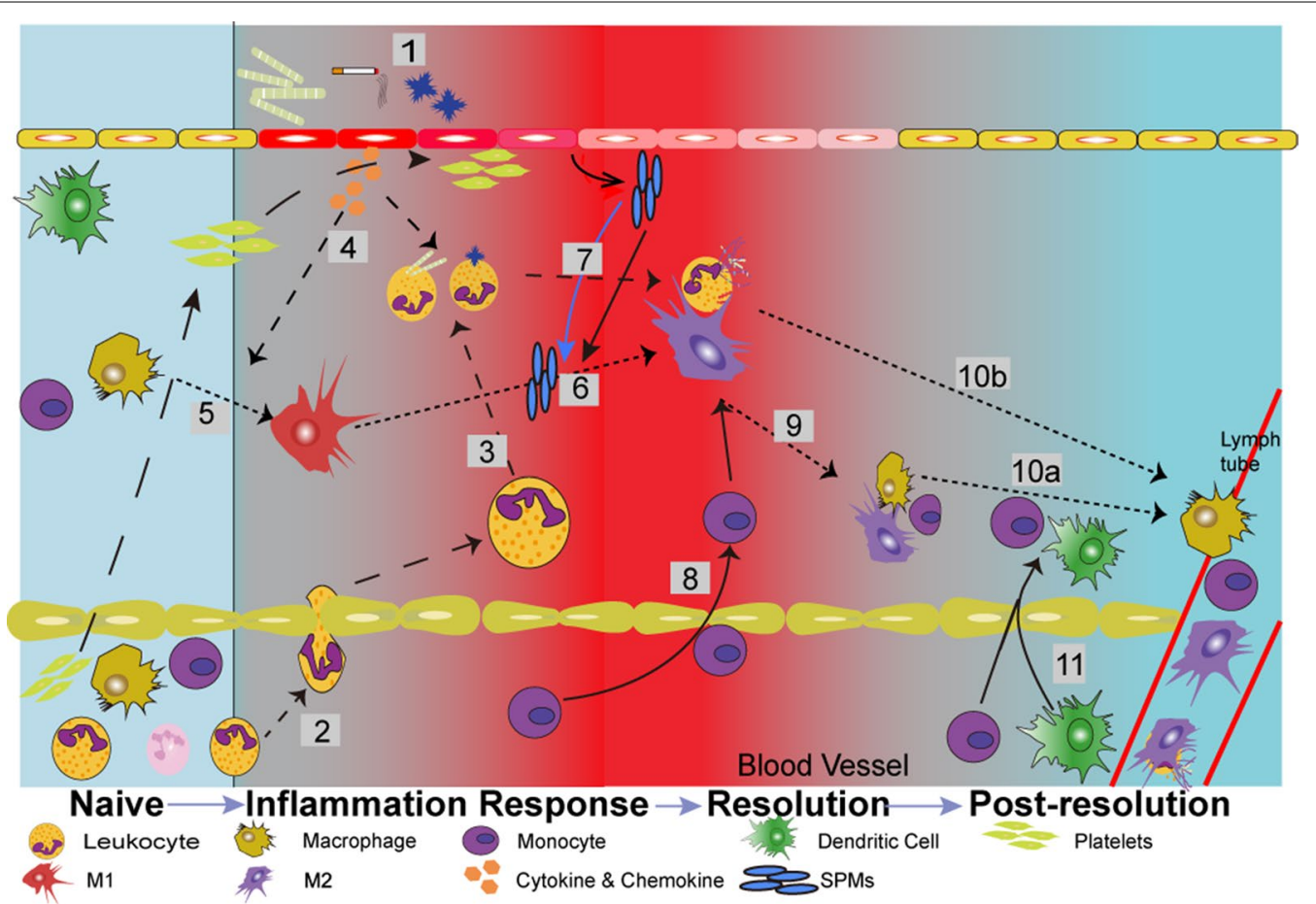

Fig. 1 Processes of the inflammatory response and resolution. Extra stimulus will cause the injury of resident cells, such as epithelial cells, and cause the inflammation onset (1). These cells will be activated and release soluble pro-inflammatory mediators, which can mediate microvascular change, and promote leukocytes influx (neutrophils or eosinophils) (2). The basic function of leukocytes is to phagocyte and thereby to eliminate microorganisms and tissue debris (3). The resident cells and leukocyte in the inflammation center will produce cytokines to induce macrophage polarization and neutrophils recruit to the inflammation center (4,5). M1 cells will transform to M2 with the pro-resolution mediator to attend to the resolution phase (6). Neutrophil apoptosis (7) followed by efferocytosis $(6,8)$ clear dysfunctional cells from the tissue. After clear the phagocytes, pro-resolving will promote macrophage program apoptosis. Excessive macrophage or non-apoptotic macrophage will leave the inflammatory site (9) or/and migrate to the lymphatic (10a,10b). At the end of inflammation resolution, resident immune cells regaining to form "adaptive immune" (11), which creates a status of "post-resolution" 
tissue healing [7]. Macrophages and DCs regulate this phase. Experiments have demonstrated that if mice are subjected to T-helper type 2 (Th2) inflammatory stimulation, then after inflammation has regressed, DCs in mice will not rapidly return to a stable state. [29]. In contrast, DCs show high expression of co-stimulatory signals, and stimulate mature DCs living in the airways for $>1$ month [30]. Studies [31] have also shown that, in inflammation resolution, MDMs continue to exist stably in tissues for months. These adaptive immune responses function as "adapted homeostasis", which can regulate the magnitude of the subsequent immune response. Therefore, this phase is considered to be an anti-inflammatory response to maintain immune cells, and may play a crucial part in determining the duration of acute innate immunity and the intensity of inflammatory stimulation.

\section{Regulation of lipid mediators in inflammation resolution}

Lipid regulatory substances have essential roles as signaling molecules in inflammation because of their small size and specific effects on limiting infection. The most important lipid-derived mediators are SPMs, which include resolvins, LXs, protectins, maresins, annexins and some peptides $[9,27]$. These substances are generated enzymatically via cyclooxygenase and lipoxygenase (LOX) pathways. They possess unique stereotypical characteristics, limit infection, and alter the lifespan of neutrophils by inhibiting their activation, migration, and infiltration. Also, SPMs and their regulatory cytokines can regulate adaptive immune system, promote the regression of inflammation, and re-establish tissue homeostasis [32, 33] (Table 1).

\section{Lipoxins}

LXs were first isolated and described in all SPMs by Chiang and Serhan in 1984 [34]. LXs, as a metabolite of the arachidonic-acid pathway, epithelial cells, neutrophils, leukocytes, and platelets are involved in its biosynthesis process. LXs can be synthesized by three major routes from arachidonic acid through three major lipoxygenases: 5-LOX, 12-LOX, and 15-LOX [9, 35, 36]. Leukotriene (LT) A4, LXA4, LXB4, and aspirin-triggered LX are synthesized starting from omega- 6 arachidonic acid [37]. Considering LXA4 as an example [38], during the initial stages of inflammation, cells release the precursor protein AnxA1 of LXA4, which is an agonist that recognizes its specific receptor FPR2/ALX. The latter triggers the calcium-ion channels in cells to accelerate influx of calcium ions $\left(\mathrm{Ca}^{2+}\right)$. The phospholipase A2, phosphoinositide 3-kinase (PI3K), and mitogen-activated protein kinase (MAPK) pathways become activated, promoting cellsurface phosphorylation FPR2/ALX receptor homodimer formation and pairs with LXA4. FPR2/ALX receptor on both phagocytes and monocytes phosphorated can induce cells to produce large amounts of interleukin (IL)-10 and promote the regression of inflammation [39]. LXA4 can inhibit the activation of serum amyloid A on the cell surface to delay apoptosis signals through phosphorylation via the FPR2/ALX pathway, and reduce the adhesion and aggregation of neutrophils [37, 40]. Otherwise, signals released by LXA4 can be combined with those of resolvin E1 to prevent an overflow of neutrophils, and thereby promote inflammation [41].

\section{Resolvins}

Resolvins were first discovered in the exudates of mice during inflammation resolution [42]. They are derived from omega-3 polyunsaturated fatty acids in the form of eicosapentaenoic acid (EPA) and docosahexaenoic acid (DHA), which combine specifically with $\mathrm{G}$ protein-coupled receptors (GPCRs) and promote the elimination of bacteria and efferocytosis. Based on the different unsaturated fatty acids derived from it, EPA can be divided into resolvin E1 (RvE1) and RvE2, and DHA can be divided into resolvin $\mathrm{D}(\mathrm{RvD})$ and neuroprotectin [42]. Studies have shown that RvE1 mainly mediates the migration and activation of the monocyte-macrophage system by binding specifically with two types of receptors, ChemR23 and LTB4 receptor 1 (BLT1), to promote the resolution phase [43-45]. In addition, RvD1 helps to promote inflammation by interacting with FPR2/ALX and GPR32 receptors on the cell surface [46]. Its aspirin-triggered epimer, AT-RvD1, as well as RvD3 and RvD5, can bind the GPR32 receptor to express on human neutrophils, lymphocytes, monocyte-macrophages, and in vascular tissues [47]. RvD2 binds to DRV2/GPR18 receptors involved in the resolution of inflammation by modulating expression of neutrophils, lymphocytes, and MDMs [48].

\section{Protectins and maresins}

Protectins and maresins are pro-inflammatory mediators derived from DHA [49]. Protectin is formed by the hydrolysis of DHA by LOX but the specific mechanism is incompletely understood. The process might be achieved through the inhibition of neutrophil aggregation and regulation of the secretion of chemokines and cytokines in combination with GPCRs to regulate the inflammatory response [50,51]. Maresin (macrophage mediator in resolving inflammation, MaR) is a novel family of SPMs. This family mainly regulates the inflammatory response by limiting neutrophil migration and stimulates macrophage phagocytosis [52, 53]. Early production of MaR1 is dependent on platelet-neutrophil interactions to participate in inflammation regulation [54]. 
Table 1 Members of SPMs family and their roles in inflammation resolution

\begin{tabular}{|c|c|c|c|c|}
\hline Mediator & & Receptors & Functions & Refs. \\
\hline \multicolumn{5}{|c|}{ Alpha-linolenic acid (omega-3) } \\
\hline & \multirow[t]{5}{*}{ Lipoxin A4 } & \multirow[t]{5}{*}{ FPR2/ALX } & Regulate leukocytes, PMNs, eosinophils, and monocytes & [177] \\
\hline & & & Promote but inhibit apoptosis process & [178] \\
\hline & & & Increase IL-10 production, and inhibit IL-6, IL-8, IL-12 expression & {$[39,179]$} \\
\hline & & & Inhibit the activation of the NF-kB pathway & [179] \\
\hline & & & Regulate tight-junction formation in airway epithelial cells & [180] \\
\hline & \multirow[t]{2}{*}{ Lipoxin B4 } & \multirow[t]{2}{*}{ GPCRs } & $\begin{array}{l}\text { Accelerate the regulation of allergic lung inflammation and airway hyper- } \\
\text { responsiveness }\end{array}$ & [181] \\
\hline & & & Inhibit the recruitment and transmigration of PMNs & {$[48,182]$} \\
\hline & \multirow[t]{3}{*}{$\begin{array}{l}\text { Aspirin- } \\
\text { triggered } \\
\text { LX (ATL) }\end{array}$} & \multirow[t]{3}{*}{ ALX/FPR } & Inhibit neutrophil chemotaxis across the endothelium and epithelium & {$[37,183]$} \\
\hline & & & Enhance clearance and accelerate resolution of pulmonary edema & {$[2,184]$} \\
\hline & & & Reduce Cox2 traffic in pain responses & [2] \\
\hline \multicolumn{5}{|c|}{ Alpha-linolenic acid (omega-3) } \\
\hline \multirow[t]{5}{*}{ EPA } & \multirow[t]{3}{*}{ RVE1 } & \multirow[t]{3}{*}{$\begin{array}{l}\text { ERV1/ } \\
\text { ChemR23; } \\
\text { BLT4 [185] }\end{array}$} & Mediate cell-migration and activation of the monocyte-macrophage system & {$[81,185]$} \\
\hline & & & Limit neutrophil infiltration, and promote macrophage phagocytosis & [186] \\
\hline & & & Enhance phagocytosis and production of anti-inflammatory cytokines & {$[60,61]$} \\
\hline & \multirow[t]{2}{*}{ RvE2 } & \multirow[t]{2}{*}{ BLT1 } & Increase macrophage phagocytosis and efferocytosis & {$[45,187]$} \\
\hline & & & $\begin{array}{l}\text { Regulate morphological changes as well as the chemotaxis and migration } \\
\text { of PMNs }\end{array}$ & [45] \\
\hline \multirow[t]{11}{*}{ DHA } & \multirow[t]{2}{*}{ RvD1 } & \multirow[t]{2}{*}{ DRV1/GPR32 } & Prevent T-cell differentiation towards Th1 and Th17 lineages & [188] \\
\hline & & & Promote inflammation and enhance macrophage clearance & {$[45,189]$} \\
\hline & \multirow[t]{2}{*}{ RvD2 } & \multirow[t]{2}{*}{ DRV2/GPR18 } & $\begin{array}{l}\text { Modulate expression of neutrophils, lymphocytes, and monocytes-mac- } \\
\text { rophages }\end{array}$ & [48] \\
\hline & & & Stimulate phagocytosis and apoptosis & [190] \\
\hline & \multirow[t]{3}{*}{ PD1 } & \multirow[t]{3}{*}{ GPCRs } & Inhibit neutrophil aggregation & {$[50,51]$} \\
\hline & & & Regulate the secretion of chemokines and cytokines & {$[50,51]$} \\
\hline & & & $\begin{array}{l}\text { Transformation of mononuclear cells, macrophages, neutrophils and plate- } \\
\text { lets }\end{array}$ & [182] \\
\hline & \multirow[t]{4}{*}{ Maresin } & \multirow[t]{4}{*}{ GPCRs } & Inhibiting neutrophil migration & {$[13,52,53]$} \\
\hline & & & Enhance recruitment of monocytes and macrophages and efferocytosis & [13] \\
\hline & & & Inhibit IL-13 production and induce formation of regulatory T cells & [46] \\
\hline & & & Induce polarization of M1 macrophages to M2 macrophages & [52] \\
\hline
\end{tabular}

\section{Regulation of inflammatory cells}

Neutrophils can survive only for several hours in peripheral blood. However, their survival can be extended by inflammatory mediators (IL-6, IL-8, or GMS-F) or lipopolysaccharide stimulation [7]. As inflammation progresses, neutrophils accumulate rapidly within the inflamed area and can digest the invading microbes. Then, the body restricts the influx of neutrophils to prevent persistent inflammation. This process, whereby the concentration gradient of chemokines and cytokines is regulated, activates the release of the pro-resolution mediators; thus, the recruitment and accumulation of neutrophils is no longer activated.
Neutrophils are the first line of defense against invading microbes. They are recruited rapidly to the center of inflammation to engulf microbial pathogens. While neutrophils engulf microbes and undergo apoptosis to break down into several fragments, they also become engulfed by macrophages, which promote resolution [55]. This complex regulatory process is carried out by signaling pathways, such as caspase-mediated endogenous or exogenous apoptosis mechanisms, and include other major pathways, such as PI3K/Akt, MAPKs, and B-cell lymphoma (Bcl)-2 [37]. The PI3K/Akt pathway can inhibit neutrophil apoptosis and promote inflammation by inhibiting the phosphorylation of apoptotic 
proteins. RvE1 and Mar1 can promote neutrophil apoptosis and inflammation regression by blocking the PI3K/ Akt pathway.

In the MAPK pathway, extracellular signal-regulated kinase (ERK) and p38MAPK are considered important regulators of neutrophil survival [56]. Furthermore, RvE, Mar, and other SPMs can promote neutrophil apoptosis and inflammation resolution by inhibiting the phosphorylation of ERK and P38MAPK [57].

Research has demonstrated that apoptotic neutrophils can up-regulate the expression of many chemokines and activate monocyte-macrophage migration to apoptosis sites [7]. LXs and lactoferrin released by neutrophils can promote monocyte/macrophage migration and inhibit neutrophil migration [58]. These apoptotic neutrophils express various types of molecules on their surface, such as phospholipids and ribosomal proteins, which macrophages can recognize. Such molecules activate the phagocytic ability of macrophages, promote the rapid and effective clearance of apoptotic cells from tissues, prevent the initiation of a secondary inflammatory response and necrosis triggered by the release of toxic substances in neutrophils and, thus, promote the resolution of inflammation [59]. The phagocytosis and apoptosis of macrophages can increase the release of the pro-inflammatory lipid mediators LXA4, RvE1, PD1, and maresin. In addition, RvE1 can reduce the production of TNF- $\alpha$ and IL- $1 \beta$, and increase the production of the anti-inflammatory factor IL-10 [60, 61]. Furthermore, RvD1 can increase the production of TNF- $\alpha$ and enhance the cell-killing ability of macrophages [62].

Neutrophils initiate antimicrobial and phagocytic activity against infection. Also, they release extracellular DNA complexes, which are called "neutrophil extracellular traps" (NETs), to regulate several infections [63]. In recent decades, NETs have been determined to play an important part in host defense and pathologic inflammation. Evidence shows that NETs are associated with pathophysiological processes in cardiovascular disease [64, 65], pancreatitis [66], asthma [67, 68], COPD [69, 70], and cancer [71]. As a protein-DNA complex, the main structures of NETs are extracellular DNA, histone, and many types of peptides, such as neutrophil elastase, myeloperoxidase, lactoferrin, gelatinase, and cathelicidins [72]. However, there still has little study about the action of SPMs on NET formation. A recent study demonstrated that LXA4 could decrease NETs release in vitro [73]. But NETosis will excessively produce after the lungs' bacterial infection in the ALX/FER2 receptor-deficient mice [73]. Moreover, RVD1 treatment of mice showed significantly low levels of NETS in aortic tissue of abdominal main pulse model animals [74]. Likewise, RVD4 treatment could decrease NETs release [74]. These studies show that SPMs might play roles in the formation of NETs and regulation in inflammation resolution.

During acute and chronic lung inflammation, many immune cells and structural cells undergo apoptosis progressively. The process by which phagocytosis (including that undertaken by macrophages, immature DCs, and atypical phagocytic cells) removes these apoptotic cells effectively is called "efferocytosis" [75, 76]. During the inflammatory response, the elimination of apoptotic cells is beneficial because it promotes the regression of inflammation and restores homeostasis in the lungs (Table 2). Specific signaling molecules are present in living cells, such as phosphatidylserine and other molecules, which are referred to as "eat me" molecules. While cells engulf pathogens and to initiate apoptosis, these cells are exocytosed and show high expression on the cell surface. Receptors on phagocytes can recognize these signals to enhance tissue homeostasis [77]. However, this effect is bidirectional; thus, phagocytes can induce the necessary cytoskeletal rearrangements to ingest the apoptotic cells and also transmit an instructive signal $[76,77]$.

Macrophages can differentiate into M1 and M2 lineages under the stimulation of different microenvironments. M1 macrophages can express most of the toll-like receptors (TLRs) and secrete IL-12, TNF- $\alpha$, IL- $1 \beta$, IL-6, and other pro-inflammatory factors $[78,79]$. During the early stages of inflammation, macrophage activation mediated by TLRs on RvD1 can increase the phagocytic ability of granulocytes and reduce the production of reactive oxygen species (ROS) to control the acute inflammation caused by oxidative stress and enhance the phagocytic function of macrophages [80]. Furthermore, RvE1 can stimulate the transformation of macrophages from the M1 phenotype to an intermediate phenotype. This is different from M2 polarization, but leads to secretion of anti-inflammatory factors such as IL-4, IL-10, and transforming growth factor (TGF)- $\beta$, and promotes inflammation resolution, vascular regeneration, and tissue repair [81].

If inflammation occurs in lung diseases, peroxisome proliferator-activated receptor (PPAR) $-\gamma$ stimulates the transformation of macrophages from the M1 lineage to the M2 lineage through a complex regulatory mechanism [82]. Moreover, RvE1 can enhance macrophage efferocytosis on apoptotic neutrophils and bacterial fragments, induce the differentiation of non-inflammatory macrophages, and release several anti-inflammatory factors, such as TGF- $\beta$ and IL-10, among others [60]. Thus, the environment in vivo can promote the conversion of the inflammatory response to inflammatory resolution and enhance host defense. In addition, efferocytosis can also increase the expression of prostaglandin (PG)E2 and 
some intracellular factors, which help to promote resolution and the restoration of homeostasis $[83,84]$.

\section{Resolution in diseases of the respiratory system}

Pneumonia, acute lung injury (ALI), acute respiratory distress syndrome (ARDS), asthma, pulmonary fibrosis, and COPD are common respiratory system diseases and carry a high incidence and poor curative effect. These diseases can severely affect the quality of life, and may even lead to death. The mechanism of action of these diseases is, in general, associated with inflammation but the exact mechanisms have yet to be elucidated (Fig. 2). However, chronic, persistent, and unresolved inflammation is a key process in the formation of such chronic airway and lung diseases. In recent years, the relationship between these chronic airway diseases and chronic inflammation has been widely recognized. The study of respiratory diseases in inflammation subsidence has made initial strides.

\section{Pneumonia}

Pneumonia is inflammation of the terminal airways, alveoli, and interstitium of the lungs. It can be caused by pathogenic microorganisms, physical and chemical factors, immune disorders, allergies, and drugs. Although most pneumonia is self-limiting, it can also be observed in chronic inflammatory foci. Furthermore, many pathogens, toxicants and allergens causing pneumonia or sepsis, which might induce acute respiratory distress syndrome (ARDS), and acute lung injury or inflammation (ALI). And the research demonstrates that these pneumonia- or sepsis-induced ALI/ARDS will promote different immune response and therapy effective [85].

A multicenter pilot study conducted in 2017 [86] reported that during community-acquired pneumonia, the levels of monounsaturated fatty acids (MUFAs) and polyunsaturated fatty acids (PUFAs) were increased significantly. The inflammatory response in the high-PUFA group of that study was increased even with a relatively moderate degree of inflammation. That finding suggests that unsaturated fatty acids have important roles during pneumonia progression. However, owing to the excessive lipid metabolism involved in the inflammatory response, PUFAs might not simply serve as an anti-inflammatory lipid medium in lung diseases.

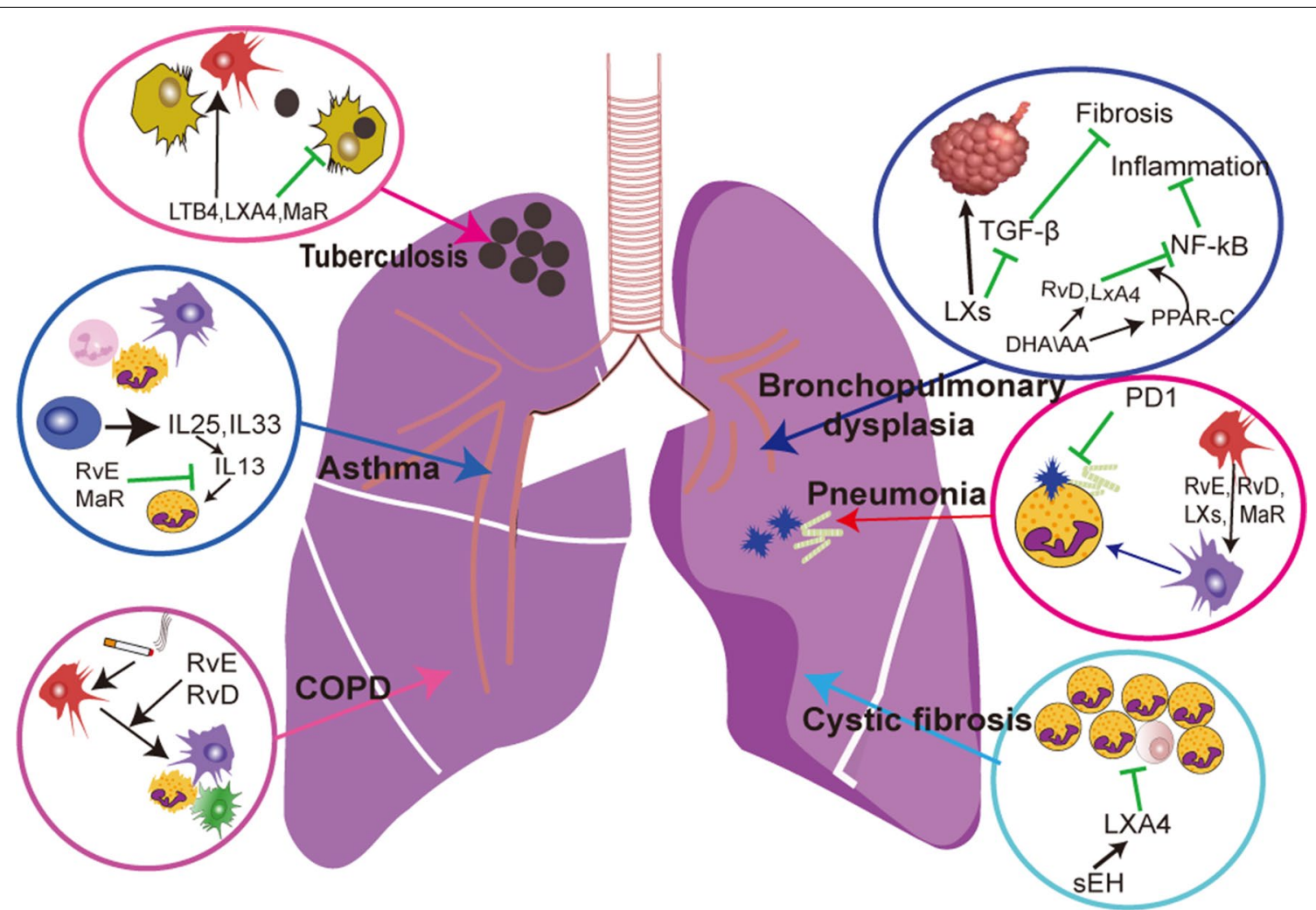

Fig. 2 Cellular mechanism for SPMs in pulmonary disease. Specialized pro-resolving mediators (SPMs) contributed to the resolution of inflammation. These endogenous mediators involved in cytokines production, pathways regulation and inflammatory cell modulation, which can affect different pathophysiologic process of these pulmonary diseases. There is the major regulation pathway of SPMs in tuberculosis, asthma, COPD, cystic fibrosis and pneumonia and bronchopulmonary dysplasia 
Based on different stages of airway inflammation and disease severity, the pro-inflammatory resolution effects of PUFAs might be impacted by several factors [87, 88]. Epidemiological studies have revealed Streptococcus pneumonia to be one of the most common pathogenic bacteria in community-acquired pneumonia. A baboon model of pneumonia induced by S. pneumoniae infection found that the levels of endogenous lipid mediators (especially RvE1) in plasma were reduced during infection. The administration of exogenous RvE, such as lipoxins, considerably relieves among such mediators and promotes the repair of damaged lung tissue [89].

Pseudomonas aeruginosa is a common infectious factor in the respiratory system [90]. The complex antibiotic resistance make these bacterial results the acute exacerbation of COPD and mortality of Cystic fibrosis (CF). Animal experiments have shown that RvD1 expression is reduced significantly in pneumonia caused by $P$. aeruginosa infection [91]. Furthermore, RvD1 can significantly inhibit the activity of the TLR- MyD88/TRIF pathway by regulating the expression of TLRs and down-regulating the expression of microRNA (miR)-21 and 155 genes. In this way, RvD1 reduces the secretion of vascular endothelial growth factor (VEGF) and C-X-C motif ligand (CXCL), and thereby prevents excessive activation of macrophages and inhibits the expression of inflammatory factors [92]. Therefore, RvD1 can be regarded as a novel treatment candidate for persistent and refractory inflammation in the lung caused by $P$. aeruginosa infection owing to its cellular functions and molecular effects in host defense against pathogens in airway mucosal tissues.

In addition, LXA4 has protective effects on infected seed coats and endothelial cells, and promotes neutrophil apoptosis through the Bcl-2 pathway to reduce inflammation persistence [93]. Higgins and colleagues [94] demonstrated that LXA4 incubated with epithelial cells could inhibit $P$. aeruginosa infection-mediated expression of the tight-junction protein zonula occludens- 1 on epithelial surfaces, which can protect and delay the bacterial's invasion. This regulation could also enhance the barrier function by promoting tight junction formation and accelerating the epithelial repair.

In a mouse model of pneumonia induced by Haemophilus influenzae infection, Croasdell and coworkers [17] found that the inflammation and damage of pulmonary tissue were persistent, and was not alleviated even after bacteria had been cleared. However, the exogenous administration of $17 \mathrm{R}-\mathrm{RvD} 1$ could regulate the transport of leukocytes to the lung. The resulting effects included reduction in the recruitment of neutrophils, acceleration of the influx of macrophages, the shifting of macrophage polarization, and reduction of the expression of IL- 6 and TNF- $\alpha$. These effects could reverse regulation of the inflammatory environment triggered by $H$. Influenzae infection [17].

Influenza viruses are the main causes of airway infection that can lead to severe pneumonia and, ultimately, death. Recently, Cilloniz and colleagues [95] found that enhancement of the pathogenicity of influenza viruses was positively correlated with the intensity of its inhibition of pro-inflammatory factors. The mortality rate could be reduced by injecting protective factors into mice infected with the H5N1 virus. This mechanism may be achieved by inhibiting RNA replication of the $\mathrm{H} 5 \mathrm{~N} 1$ virus [96]. Furthermore, PD1 has been demonstrated to be a potential drug to prevent the spread of the $\mathrm{H} 5 \mathrm{~N} 1$ virus. In a study of the H1N1 virus, Ramon and colleagues [97] found that the RvD precursor, 17(S)-hydroxydocosahexaenoic acid (17-HDHA), could promote a significant increase in the levels of anti-H1N1 antibodies in the serum, as well as increase the number of antibody-secreting cells in the bone marrow of mice.

Studies have demonstrated that LXs and protectin inhibit viral replication, reduce the severity of inflammation, promote neutrophil apoptosis, regulate neutrophil chemotaxis, and can reduce mortality significantly [98]. Although reports on the efficacy of SPMs on coronavirus infection-induced pneumonia are lacking, SPMs could be a potential treatment for retarding the associated inflammatory response and improving the prognosis, but this hypothesis merits further study.

\section{Tuberculosis (TB)}

TB is associated with one of the highest numbers of deaths by infectious disease worldwide. According to the World Health Organization, there are $>10$ million new cases of TB each year [99]. These increased morbidity and mortality levels from TB result from a complex disease process triggered by the pathogen Mycobacterium tuberculosis, which modulates inflammation at different stages intracellularly [100].

Granuloma formation is strongly correlated with inflammation regulation [101]. Local imbalance of inflammation results in extensive necrosis of granulomas and release of their liquefied contents into the bronchi and, thus, has dual roles in protection and disease [102]. Some inflammatory factors regulate chemokines and cytokines (e.g., IL-22), which prevent pathogenic epithelial cell-destructive inflammation by inhibiting the release of matrix metalloproteases and PMN-recruiting chemokines and promoting aberrant proliferation and differentiation of epithelial cells[103, 104]. Neutrophilic proteases can cleave IL-22R1 on epithelial cells and impair IL-22-dependent antimicrobial protein production from epithelial cells [105]. 
Studies [106-108] have shown that SPMs such as LTB4, LXA4, PGE2, and PGF2 $\alpha$ play important parts in the susceptibility and pathogenesis of TB. Research on lipid-derived mediators suggests that LXs and maresin families are the most abundant pro-resolving lipid mediators in individuals suffering from TB [109]. Such mediators modulate the balance between pro-inflammatory and pro-resolving reactions. Furthermore, LXA4 might accelerate the progress of active TB. In contrast, PGs (especially $\mathrm{PGE}_{2}$ and $\mathrm{PGF}$ ) play an important part in immunosuppression during infections [109]. However, the specific roles and functions of these SPMs in TB are not clear.

During TB progression, macrophages have key roles in inflammation regulation. PPAR- $\gamma$ provides a major pathway in inflammation resolution, promoting the survival and growth of M. tuberculosis in macrophages in in vitro models, and can regulate the expression, polarization, and anti-inflammation of alveolar macrophages [110]. The latter also have potential roles in the promotion of $M$. tuberculosis growth in the lung [110, 111]. Research on TB treatment has demonstrated that the administration of LXs and $\mathrm{PGE}_{2}$ is useful in restricting the development of inflammation during the early phases [112].

\section{Asthma}

Asthma could affect as many as 40 million people worldwide by 2025 [113]. Asthma obstructs airway ventilation, which is caused by chronic inflammation and hyperresponsiveness of the airways. Blood vessel proliferation in the bronchi, infiltration of inflammatory cells, mucus hypersecretion, and airway remodeling are the primary asthma pathophysiology [114].

Asthma onset can be divided into two phases [115]. Early asthma attacks could be considered to be due to acute inflammation of the airways [115]. If many allergens enter the body, they promote extensive accumulation of IgE, which mediates the degranulation of mast cells and eosinophils, and activates DCs and type 2 innate lymphoid cells (ILC2) to penetrate the bronchial mucosa. The release of LTs, histamine, PGs, and cytokines trigger an acute inflammatory response of the cells in the airways, thereby causing airway damage.

During the later phases of asthma, chronic airway inflammatory lesions may appear [115]. Many apoptotic epithelial cells and neutrophils accumulate in the airways of asthma patients. Eosinophils and macrophages begin to engulf and clear apoptotic cells in large quantities to maintain homeostasis. However, the number of airway macrophages in patients with severe asthma is reduced significantly compared with healthy people. Thus, complete clearance of apoptotic cells in patients with asthma is difficult, which might be related to a reduction in the production of anti-inflammatory eicosanoic acid or regulators of soluble hydrolysis. Lower levels of LXA4 in the serum, bronchoalveolar lavage fluid (BALF), and induced sputum are positively correlated with asthma severity and are closely related to oxidative stimulation and changes in lung function [116].

Studies on ILC2 in asthma have shown that it can stimulate epithelial cells to secrete the inflammatory factors IL-25 and IL-33, and mast cells to release PGD2, which can stimulate IL-13 secretion to induce bronchial hyperresponsiveness $[115,117]$. Furthermore, IL-C2 promotes the recruitment of eosinophils by producing IL-5 [115]. Several pro-inflammatory factors (including eicosanoids, cytokines, chemokines, and growth factors that contribute to asthma symptoms and bronchial hyperresponsiveness) are secreted by activated epithelial cells and smooth muscle cells and may persist during chronic inflammation. In vitro, SPMs can inhibit the migration of eosinophils and neutrophils. Simultaneously, SPMs in combination with the expression of the transient receptor potential pathway can activate lung sensory neurons, and thereby regulate IL-C2 activity, promote the proliferation of bronchial epithelial cells, and enhance the repair and recovery of tissue [50, 51].

In addition, SPMs can inhibit lung fibrosis by inhibiting the proliferation of lung fibroblasts [101]. Animal experiments have demonstrated that PD1 can effectively inhibit the proliferation of eosinophils and $\mathrm{T}$ lymphocytes in the airways [118]. Maresin 1 and PD1 can inhibit the production of inflammatory factors (e.g., IL-5 and IL-13) [115]. Furthermore, PD1, like RvE1, is produced by increased levels of the chemokine receptor CCRX 5 on the surface of apoptotic PMNs. Expression of maresin 1 is regulated by the interaction between TGF- $\beta$ and IL-C2, which promote the dissipation of lung inflammation $[10,119]$. In addition, treatment with RvE1 in allergic inflammation increases the formation of lipoproteins, directly inhibits the production of IL-23 and IL-17 in the lung, and promotes the cytotoxicity of natural killer cells [120]. These effects support the role of RvE1 in promoting the resolution of allergic pulmonary inflammation through other inflammatory pathways.

There are some patients with a low type 2 cytokine expression, which is called non-Th2 inflammation in asthma. This type of asthmatics always has a mixed granulocytic and chronic inflammatory response in the airway. Inadequately treatment with corticosteroids caused a persistent symptom and a higher exacerbation frequency [121]. For these patients, SPMs might combine with the receptors on NK cells or regulate eosinophilia and neutrophils' anti-inflammation function to inhibit the exuberant airway inflammation. 
In an animal model of allergic asthma [122] characterized by eosinophilia, the TLR-7 receptor was able to recognize single-stranded RNA from the rhinovirus and self RNA during injury and necrosis of tissue. During the inflammatory response, the administration of TLR7 and other activators up-regulated DHA-derived SPMs such as PD-1, 17-HDHA, and 14-HDHA [123]. Therefore, the main mechanism of TLR7-mediated relief of airway inflammation is converting endogenous DHA to its bioactive products. However, the specific mechanism is not yet clear, and further research is needed. Recent research $[46,124]$ has shown that a continuous inflammatory response enhances oxidative stress in patients with severe asthma. Furthermore, the release of a large amount of soluble epoxide hydrolase can lead to reduced synthesis of 14,15-epoxyeicosatrienoic acid (EET), and a considerably reduced ability to synthesize LXs in the airways, which can reduce the resolution of lung inflammation.

Animal experiments have shown that LXA4 and its stable analogs have important effects on the prevention of allergic pulmonary inflammation. Furthermore, LXA4 can promote the repair of airway endothelial cells in asthma, up-regulate the expression of the tight-junction proteins occludin- and chudin-1, maintain transepithelial resistance, and maintain homeostasis of airway endothelial cells [125]. Simultaneously, LXs and LTs have a competitive inhibitory effect. Thus, LXs can effectively inhibit tracheal contraction, reduce airway hyperresponsiveness and mucous epithelial metaplasia, and promote the resolution of pulmonary inflammation $[46,115]$.

Glucocorticoids are considered to be the main antiinflammatory drugs in asthma treatment. Glucocorticoids can activate ALX/FPR2 receptors jointly to regulate the high expression of anti-inflammatory factors, such as LXs and annexin A1 (which activates the adaptive immune response), increase the phagocytic capacity of macrophages, and reduce airway hyperresponsiveness [126]. Low-dose aspirin can reduce the expression of proinflammatory mediators, and can promote the expression of endogenous SPMs (e.g., resolvin and LXs), and thereby promote the regression of inflammation [127]. Furthermore, SPMs offer the potential to control inflammation and augment host defense in the non-Th2 inflammation in severe asthma patients. Some analogs and agonists of SPM have entered phase-I or -II clinical trials, and there is evidence that these drugs can promote the resolution of inflammation in asthma [128].

\section{COPD}

COPD is a major pulmonary disease with high morbidity and mortality worldwide. COPD pathogenesis is associated with chronic and persistent inflammation in the lung, which correlates with obstruction and limitation of the small airways. The primary disease and inflammatory response in COPD can cause tissue damage and irreversible organ injury in such cases [129]. Current understanding of COPD is deepening, and the disease can now be divided into several phenotypes based on symptoms or tests, with a yet unclear pathogenesis.

A review by Barnes [130] showed that the major mechanism of airway obstruction in COPD is the loss of elastic recoil, which is caused by proteolytic destruction of the lung parenchyma. Thus, reversal of this condition with medication is usually impossible. Otherwise, preventing the occurrence and persistence of inflammation and enzymatic disease processes could inhibit COPD progression and prevent fibrosis [130]. Therefore, research into the various ways by which the subsidence of inflammation or the elimination of persistent external stimuli may be promoted would be helpful for the treatment of patients with early COPD or acute exacerbations of COPD, and could facilitate the repair of airway injuries.

The levels of RvD1 and LXs in the sputum, serum, and exhaled breath of COPD patients are reduced significantly compared with those in healthy people $[131,132]$. The levels of LXA4 [133] and LXB4 in the exhaled breath of patients with moderate-to-severe COPD is reduced significantly, and is accompanied by a significant increase in the levels of pro-inflammatory factors [132]. The exogenous administration of RvD1 can significantly reduce the number of neutrophils and cells induced by the stimulation of cigarette smoke, while also reducing inflammation, oxidative stress, and even cell death [132, 134]. Those studies suggest that the persistence of chronic inflammation may destroy the pro-resolution pathway in the lung tissue of patients with COPD. SPMs reduce the incidence of emphysema by controlling chronic inflammation.

The transcription and synthesis of lipids is dependent upon several transcription factors, such as PPARs $[135,136]$, liver $\mathrm{X}$ receptors [137], and sterol regulatory element-binding proteins $[138,139]$. These transcription factors may have particular importance in the pathophysiology or treatment of COPD and other diseases. In patients with COPD, PPAR- $\gamma$ expression is down-regulated in lung tissue, epithelial cells, and myeloid DCs $[140,141]$. Furthermore, PPAR- $\gamma$ can promote polarization of M2 macrophages, which enhances the clearance of apoptotic neutrophils, and improves anti-inflammatory efficiency and the capacity for tissue repair [140, 142, 143].

Increased fibrosis in small airways is an important mechanism of disease progression in patients with COPD, and is speculated to be caused by chronic inflammation. This hypothesis suggests that efficacious antiinflammatory treatment could prevent fibrosis [144]. 
Table 2 Different cell-type in inflammation resolution action

\begin{tabular}{|c|c|c|c|}
\hline Cell type & General function & Actions in inflammation resolution & Ref. \\
\hline Neutrophils & $\begin{array}{l}\text { Phagocytosis } \\
\text { Pro-inflammation } \\
\text { NETosis }\end{array}$ & $\begin{array}{l}\text { Accelerate cytokines and chemokines secretion } \\
\text { Apoptosis } \\
\text { NETosis } \\
\text { Egress to Lymph node }\end{array}$ & {$[7,51,55]$} \\
\hline Macrophages & $\begin{array}{l}\text { PRR } \\
\text { Phagocytosis } \\
\text { Efferocytosis }\end{array}$ & $\begin{array}{l}\text { M2 formation } \\
\text { Effercytosis } \\
\text { Secrete pro-inflammation cytokines, such as IL-10, TGF- } \beta \\
\text { Egress to Lymph nodes } \\
\text { Promote SPMs, including resolvins, maresins, protectins formation }\end{array}$ & {$[80,81,191]$} \\
\hline Eosinophils & $\begin{array}{l}\text { Phagocytosis } \\
\text { Cytotoxic substances }\end{array}$ & $\begin{array}{l}\text { IL-4, IL-13 secretion } \\
\text { Lipoxin A4 production }\end{array}$ & {$[46]$} \\
\hline Mast cells & Secretion of vasoactive substances & Mediators secretion & {$[51]$} \\
\hline DCs & $\begin{array}{l}\text { Sensing DAMPs } \\
\text { PRR }\end{array}$ & $\begin{array}{l}\text { TGF-b, IL-10 secretion } \\
\text { Inhibits migration } \\
\text { Maintain the homeostasis after inflammation resolute }\end{array}$ & {$[20,21]$} \\
\hline ILC2 & $\begin{array}{l}\text { Produce type } 2 \text { cytokines } \\
\text { Express surface markers and receptors for } \\
\text { chemokine }\end{array}$ & $\begin{array}{l}\text { Inhibits IL-13 secretion, } \\
\text { Express the chemokine receptors CXCR6 and CCR9 } \\
\text { IL-25, IL-33, and thymic stromal lymphopoietin (TSLP) to induce inflam- } \\
\text { mation formation and eosinophilic infiltration }\end{array}$ & {$[115,117,192]$} \\
\hline Epithelial cells & $\begin{array}{l}\text { Physical barrier } \\
\text { Mucociliary clearance }\end{array}$ & $\begin{array}{l}\text { Maintain mucosal integrity and to modulate local immune responses } \\
\text { Decrease and limit pro-inflammatory mediators and proteins } \\
\text { Increases proliferation after acid injury and promote tissue repair } \\
\text { Immune regulator }\end{array}$ & {$[24,193]$} \\
\hline Endothelial cells & Regulation transduction and exudation & $\begin{array}{l}\text { Inhibits TNF-a, IL-1b and IL-18 secretion } \\
\text { Blocks the generation of reactive oxygen species }\end{array}$ & {$[51]$} \\
\hline Fibroblasts & $\begin{array}{l}\text { Tissue support } \\
\text { Cytokine secretion }\end{array}$ & $\begin{array}{l}\text { Growth factors inducement } \\
\text { Inhibits CTGF-induced proliferation }\end{array}$ & {$[46,194]$} \\
\hline
\end{tabular}

Chronic persistent inflammation stimulates alveolar epithelial cells continuously to cause repeated tissue repair and scar formation. Eventually, the movement of the alveolar wall becomes restricted, and the small airways become stenosed, which limits gas exchange and promotes emphysema.

In addition, the polarization of macrophages under the stimulation of cigarette smoke plays an important part in COPD pathogenesis. Under the stimulation of cigarette smoke, the classical pathway of macrophages is activated to produce M1 macrophages, which secrete pro-inflammatory factors. If M2 macrophages are activated through alternative pathways, they can effectively remove inflammatory cells and apoptotic cells from the airways, and promote the subsidence of inflammation as anti-inflammation factors $[145,146]$.

Studies have shown that resolvins can induce macrophages to differentiate into the M2 lineage [132]. Studies on cigarette smoke-stimulated macrophages have shown that RvE1 promotes macrophages recruitment, significantly up-regulates expression of anti-inflammatory factors, and reduces levels of inflammatory response factors in culture supernatants [147]. Similarly, RvD1supplemented macrophages are significantly activated to the M2 type, which occurs concomitantly with an increase in IL-10 secretion and significant improvement in the phagocytic capacity of macrophages [148]. Therefore, SPMs may play an important part and have emerging therapeutic importance in controlling COPD onset caused by cigarette smoke via the induction of macrophage polarization.

\section{ALI/ARDS}

A severe injury or infection in the lung can activate leukocyte recruitment, and preserve tissue homeostasis. However, an over-reactive inflammatory response might increase the exosmosis and infiltration of leukocytes in normal tissue. This observation suggests that an excessive inflammatory response can cause secondary lung injury and may even cause ARDS, a common (but acute) disease with a high mortality. Several methods have been used widely in ALI treatment but few are useful during early inflammation. In addition, sepsis and systemic inflammation are related to the pathogenesis of ALI/ARDS [149]. SPMs can potentially regulate the systemic inflammatory response and inhibit sepsis. They have been demonstrated to be the major factors in how the inflammation wrought by ALI/ARDS is resolved [54]. Therefore, SPMs can potentially promote regression as a new treatment regimen for ALI/ARDS. 
During the early phases of ALI, disease progression is mediated by the interaction between platelets and neutrophils, which promote the secretion of LXs and maresin $1[54,150]$. According to research conducted on BALF, exogenous AT-RvD1, AT-RvD3, and RvE1 help to prevent continuous damage to pulmonary tissue. This is achieved by reducing the number of inflammatory cells exuded (especially leukocytes), reducing the release of pro-inflammatory factors, and repairing bronchial epithelial cells $[151,152]$. In addition, AT-RvD1 and RvE1 activate and polarize macrophages to the M2 lineage, thereby accelerating bacterial phagocytosis [153]. Qi and colleagues showed that LXA4, as a major regulator of the miR-21/PTEN-AKT pathway, can promote sodium ion $\left(\mathrm{Na}^{+}\right)$entry into type-II alveolar cells by up-regulating the expression of subunits $\delta$ and $\gamma$ proteins on $\mathrm{Na}^{+}$channels and aquaporin 5, thereby increasing clearance of alveolar fluid [154].

\section{Cystic fibrosis (CF)}

A single gene mutation called the cystic fibrosis transmembrane conductance regulator (CFTR) causes CF formation. CF leads to increased secretion of respiratory mucus, recurrent airway infections and, eventually, pulmonary failure. Genetic studies of CF patients have shown that they carry a gene polymorphism encoding prostaglandin-endosperm synthase 2 , which reduces the secretion of pro-inflammatory factors and improves the clinical condition [155]. LXs can inhibit neutrophil infiltration, remove pathogenic bacteria, and effectively improve CF in mice. Like asthma and COPD, the expression of LXA4 in the BALF of patients with CF is also reduced significantly $[98,156]$. Furthermore, levels of DHA and its derivative, Mar1, are also reduced significantly in patients with CF $[157,158]$.

Studies on lipid-mediated agents in the airways of patients with CF have shown lower levels of lipoproteins and SPMs compared with those in healthy controls [157, 158]. In addition, patients with detectable levels of RvE1 in the respiratory tract have better lung function than patients without detectable levels of RvE1 [156]. Moreover, in an animal model of CF, the exogenous administration of soluble epoxide hydrolase has been shown to inhibit the intracellular levels of 15-epi-LXA4, reduce neutrophil infiltration into the airways, and improve lung function $[159,160]$.

\section{Bronchopulmonary dysplasia (BPD)}

BPD is common in premature infants. The mortality associated with BPD is high, and even survivors might live with various sequelae that could affect basic language skills or cognitive function. BPD pathogenesis is not clear but early supplementation with PUFAs may play a role in promoting lung maturity in infants $[161,162]$. DHA and arachidonic acid can stimulate PPAR-C and/or directly synthesize RvD1 and LXA4 by inhibiting activation of nuclear factor-kappa B [163, 164]. These actions stop the inflammatory response, reduce the lung injury caused by hyperoxia, and delay BPD development [163, 164]. Although RvD1 can promote the dissipation of lung inflammation, it cannot affect the production of other VEGFs or members of the TGF- $\beta$ family, nor the expression of BMP/Smad signaling proteins under high levels of oxygen exposure $[165,166]$.

Furthermore, LXA4 can promote the formation, reduce the average spacing between, and effectively increase the number of alveoli $[167,168]$. In addition, TGF- $\beta$ expression in newborn mice exposed to hyperoxia is decreased in the initial stages BPD, and is increased subsequently as the disease progresses. The LXs that regulate the TGF- $\beta$ signaling pathway not only inhibit the proliferation of NIH/3T3 fibroblasts [169], but also down-regulate expression of the factors related to pulmonary fibrosis (e.g., collagen I, elastin, lysine oxidase-2, matrix metalloproteinases- 2 and 9, and tissue metalloproteinase inhibitor-11) to exert protective effects in BPD induced by hyperoxia in newborn mice [170-172].

\section{Conclusions}

Inflammation response and resolution are complex processes which involve a huge number of immune cells and regulatory factors. The dysregulation of inflammation resolution is the primary pathophysiology of disease development. Therefore, the direct or indirect clearance of pathogens via all types of immune cells limits any overlap between inflammatory phases and prevents chronic inflammation development. SPMs family, their pathways, and receptors could provide a basis for new approaches for treating inflammation-associated diseases, especially in respiratory diseases.

Pneumonia and TB are caused by various microbial factors and produce a complex immune response. Many factors can cause pneumonia. Over the past few decades, coronaviruses have repeatedly posed a public health concern. The coronavirus infection-induced alveolar, lung tissue, and extra-pulmonary damage are major caused by the "inflammatory storms" and immune responses. They also cause higher mortality rates than those elicited by pneumonia due to infection with influenza viruses. Continuing research on coronaviruses has shown that they can elicit an early, rapid immune response. The inflammatory storm might cause lung tissue damage, impair function, and reduce vital capacity. In addition to the pathogenicity of the virus, the body's inflammatory response also has a vital role in cases of coronavirus infection-induced lung injury [173]. Recent 
studies show that Omega-3 fatty acids, specifically EPA and DHA, could reduce the risk of ARDS and the need of intensive care unit (ICU) admission in coronavirus disease 2019(COVID-19) [174, 175]. Moreover, a traditional Chinese medicine research has shown that the inhibition of the arachidonic-acid metabolic pathway potentially inhibits the release of inflammatory factors and alleviates the "cytokine storm" in the early infectious phase [176]. These researches suggest that SPMs might be a novel target for the rapidly inflammation reaction in the future.

Otherwise, SPMs such as LXA4, RvE1, and maresins are potential receptors to limit tissue injury in diseases of persistent inflammation. Allergies and chronic inflammation in patients with asthma or COPD should be treated with SPMs to modulate the activity of neutrophils, eosinophils, NETosis and macrophages, and thereby restore host homeostasis. Other lung diseases, including CF and BPD, show complex pathophysiology. Nevertheless, SPMs target receptors or regulate downstream processes, such as those associated with EET, to modulate inflammation pathways during the early phases of disease to prevent further progression.

In this review, we summarize the mechanism and research process of SPMs in inflammation resolution, especially in pulmonary disease. With the deep research on SPMs, the role of SPMs on inflammation resolution in different inflammation phases has been confirmed. Each SPMs potentially affects the inflammatory response and resolution, and even participation in tissue repair. Therefore, the anti-inflammatory potential of SPMs and their analogs could be a novel therapeutic approach for the treatment of chronic pulmonary and respiratory tract diseases in the future.

\section{Acknowledgements}

Not applicable.

\section{Authors' contributions}

AY conceived, wrote, edited and prepared the figures and tables in this manuscript. YW wrote the manuscript. GY and HW edited the manuscript. All authors read and approved the final manuscript.

\section{Funding}

The study was supported by the National Natural Science Foundation of China (81700038), the National Natural Science Foundation of China (81870029), Beijing Hospitals Authority Youth Programme (QML20180107), the Capital's Funds for Health Improvement and Research (2018-2-2024) and the Beijing Natural Science Foundation (7204247).

\section{Availability of data and materials}

Not applicable.

\section{Declarations}

Ethics approval and consent to participate Not applicable.

\section{Consent for publication}

Not applicable.

\section{Competing interests}

The authors declare that they have no competing interests.

Received: 5 August 2020 Accepted: 30 June 2021

Published online: 14 July 2021

\section{References}

1. Medzhitov R. Origin and physiological roles of inflammation. Nature. 2008:454(7203):428-35. https://doi.org/10.1038/nature07201.

2. Serhan CN, Yacoubian S, Yang R. Anti-inflammatory and proresolving lipid mediators. Annu Rev Pathol. 2008;3:279-312. https://doi.org/10. 1146/annurev.pathmechdis.3.121806.151409.

3. Nathan C, Ding A. Nonresolving inflammation. Cell. 2010;140(6):871-82. https://doi.org/10.1016/j.cell.2010.02.029.

4. Taams LS. Inflammation and immune resolution. Clin Exp Immunol. 2018;193(1):1-2. https://doi.org/10.1111/cei.13155.

5. McFarland HF, Martin R. Multiple sclerosis: a complicated picture of autoimmunity. Nat Immunol. 2007;8(9):913-9. https://doi.org/10.1038/ ni1507.

6. Whittington RA, Planel E, Terrando N. Impaired resolution of inflammation in Alzheimer's disease: a review. Front Immunol. 2017;8:1464. https://doi.org/10.3389/fimmu.2017.01464.

7. Fullerton JN, Gilroy DW. Resolution of inflammation: a new therapeutic frontier. Nat Rev Drug Discov. 2016;15(8):551-67.

8. Levy BD, Clish CB, Schmidt B, et al. Lipid mediator class switching during acute inflammation: signals in resolution. Nat Immunol. 2001;2(7):612-9. https://doi.org/10.1038/89759.

9. Serhan CN, Chiang N, Dalli J, Levy BD. Lipid mediators in the resolution of inflammation. Cold Spring Harb Perspect Biol. 2014;7(2): a016311.

10. Levy BD, Kohli P, Gotlinger K, et al. Protectin D1 is generated in asthma and dampens airway inflammation and hyperresponsiveness. J Immunol. 2007;178(1):496-502.

11. Serhan CN. Resolution phase of inflammation: novel endogenous antiinflammatory and proresolving lipid mediators and pathways. Annu Rev Immunol. 2007;25:101-37. https://doi.org/10.1146/annurev.immun ol.25.022106.141647.

12. Spite $\mathrm{M}$, Serhan $\mathrm{CN}$. Novel lipid mediators promote resolution of acute inflammation: impact of aspirin and statins. Circ Res. 2010;107(10):1170-84. https://doi.org/10.1161/CIRCRESAHA.110. 223883.

13. Serhan CN, Dalli J, Karamnov S, et al. Macrophage proresolving mediator maresin 1 stimulates tissue regeneration and controls pain. FASEB $J$. 2012;26(4):1755-65. https://doi.org/10.1096/fj.11-201442.

14. Souza DG, Fagundes CT, Amaral FA, et al. The required role of endogenously produced lipoxin A4 and annexin-1 for the production of IL-10 and inflammatory hyporesponsiveness in mice. J Immunol. 2007;179(12):8533-43. https://doi.org/10.4049/jimmunol.179.12.8533.

15. Leitch $A E$, Duffin $R$, Haslett $C$, et al. Relevance of granulocyte apoptosis to resolution of inflammation at the respiratory mucosa. Mucosal Immunol. 2008;1(5):350-63. https://doi.org/10.1038/mi.2008.31.

16. Duvall MG, Bruggemann TR, Levy BD. Bronchoprotective mechanisms for specialized pro-resolving mediators in the resolution of lung inflammation. Mol Aspects Med. 2017;58:44-56.

17. Croasdell A, Lacy SH, Thatcher TH, Sime PJ, Phipps RP. Resolvin D1 dampens pulmonary inflammation and promotes clearance of nontypeable haemophilus influenzae. J Immunol. 2016;196(6):2742-52.

18. Recchiuti A, Mattoscio D, Isopi E. Roles, actions, and therapeutic potential of specialized pro-resolving lipid mediators for the treatment of inflammation in cystic fibrosis. Front Pharmacol. 2019;10:252.

19. Takeuchi O, Akira S. Pattern recognition receptors and inflammation. Cell. 2010;140(6):805-20.

20. Martinon F, Mayor A, Tschopp J. The inflammasomes: guardians of the body. Annu Rev Immunol. 2009;27:229-65.

21. Newton K, Dixit VM. Signaling in innate immunity and inflammation. Cold Spring Harb Perspect Biol. 2012. https://doi.org/10.1101/cshpe rspect.a006049.

22. de Oliveira S, Rosowski EE, Huttenlocher A. Neutrophil migration in infection and wound repair: going forward in reverse. Nat Rev Immunol. 2016;16(6):378-91. 
23. Abdulkhaleq LA, Assi MA, Abdullah R, Zamri-Saad M, Taufiq-Yap YH, Hezmee M. The crucial roles of inflammatory mediators in inflammation: a review. Vet World. 2018;11(5):627-35.

24. Hiemstra PS, McCray PB Jr, Bals R. The innate immune function of airway epithelial cells in inflammatory lung disease. Eur Respir J. 2015;45(4):1150-62

25. Sansbury BE, Spite M. Resolution of acute inflammation and the role of resolvins in immunity, thrombosis, and vascular biology. Circ Res. 2016;119(1):113-30

26. Reville K, Crean JK, Vivers S, Dransfield I, Godson C. Lipoxin A4 redistributes myosin IIA and Cdc42 in macrophages: implications for phagocytosis of apoptotic leukocytes. J Immunol. 2006;176(3):1878-88.

27. Serhan CN. Treating inflammation and infection in the 21 st century: new hints from decoding resolution mediators and mechanisms. FASEB J. 2017;31(4):1273-88.

28. Newson J, Stables M, Karra E, et al. Resolution of acute inflammation bridges the gap between innate and adaptive immunity. Blood. 2014;124(11):1748-64.

29. van Rijt LS, Vos N, Willart M, et al. Persistent activation of dendritic cells after resolution of allergic airway inflammation breaks tolerance to inhaled allergens in mice. Am J Respir Crit Care Med. 2011;184(3):303-11.

30. Schwarze J, Mackenzie KJ. Neosensitization to allergens after resolution of allergic airways inflammation: a new role for airway dendritic cells. Am J Respir Crit Care Med. 2011;184(3):283-4.

31. Kumar V. Macrophages: the potent immunoregulatory innate immune cells. London: IntechOpen; 2019.

32. Dennis EA, Norris PC. Eicosanoid storm in infection and inflammation. Nat Rev Immunol. 2015;15(8):511-23.

33. Bennett M, Gilroy DW. Lipid mediators in inflammation. Microbiol Spectr. 2016. https://doi.org/10.1128/microbiolspec.MCHD-0035-2016.

34. Chiang N, Serhan CN. Structural elucidation and physiologic functions of specialized pro-resolving mediators and their receptors. Mol Aspects Med. 2017:58:114-29.

35. Chandrasekharan JA, Sharma-Walia N. Lipoxins: nature's way to resolve inflammation. J Inflamm Res. 2015:8:181-92.

36. Serhan CN, Sheppard KA. Lipoxin formation during human neutrophilplatelet interactions. Evidence for the transformation of leukotriene A4 by platelet 12-lipoxygenase in vitro. J Clin Invest. 1990;85(3):772-80.

37. Clària J, Serhan CN. Aspirin triggers previously undescribed bioactive eicosanoids by human endothelial cell-leukocyte interactions. Proc Natl Acad Sci U S A. 1995;92(21):9475-9.

38. Ye RD, Boulay F, Wang JM, et al. International union of basic and clinical pharmacology. LXXIII. Nomenclature for the formyl peptide receptor (FPR) family. Pharmacol Rev. 2009;61(2):119-61.

39. Wu J, Ding DH, Li QQ, Wang XY, Sun YY, Li LJ. Lipoxin A4 regulates lipopolysaccharide-induced BV2 microglial activation and differentiation via the notch signaling pathway. Front Cell Neurosci. 2019;13:19.

40. Bena S, Brancaleone V, Wang JM, Perretti M, Flower RJ. Annexin A1 interaction with the FPR2/ALX receptor: identification of distinct domains and downstream associated signaling. J Biol Chem. 2012;287(29):24690-7.

41. Gastardelo TS, Damazo AS, Dalli J, Flower RJ, Perretti M, Oliani SM. Functional and ultrastructural analysis of annexin A1 and its receptor in extravasating neutrophils during acute inflammation. Am J Pathol. 2009;174(1):177-83.

42. Serhan CN, Chiang N, Van Dyke TE. Resolving inflammation: dual antiinflammatory and pro-resolution lipid mediators. Nat Rev Immunol. 2008:8(5):349-61.

43. Arita M, Ohira T, Sun YP, Elangovan S, Chiang N, Serhan CN. Resolvin E1 selectively interacts with leukotriene B4 receptor BLT1 and ChemR23 to regulate inflammation. J Immunol. 2007;178(6):3912-7.

44. Ohira T, Arita M, Omori K, Recchiuti A, Van Dyke TE, Serhan CN. Resolvin E1 receptor activation signals phosphorylation and phagocytosis. J Biol Chem. 2010;285(5):3451-61.

45. Pirault J, Bäck M. Lipoxin and resolvin receptors transducing the resolution of inflammation in cardiovascular disease. Front Pharmacol. 2018:9:1273.

46. Basil MC, Levy BD. Specialized pro-resolving mediators: endogenous regulators of infection and inflammation. Nat Rev Immunol. 2016;16(1):51-67.
47. Duvall MG, Levy BD. DHA- and EPA-derived resolvins, protectins, and maresins in airway inflammation. Eur J Pharmacol. 2016;785:144-55.

48. Kytikova O, Novgorodtseva T, Denisenko Y, Antonyuk M, Gvozdenko T. Pro-resolving lipid mediators in the pathophysiology of asthma. Medicina (Kaunas). 2019. https://doi.org/10.3390/medicina55060284.

49. Serhan CN, Dalli J, Colas RA, Winkler JW, Chiang N. Protectins and maresins: new pro-resolving families of mediators in acute inflammation and resolution bioactive metabolome. Biochim Biophys Acta. 2015:1851(4):397-413.

50. Park CK, Lü N, Xu ZZ, Liu T, Serhan CN, Ji RR. Resolving TRPV1- and TNFa-mediated spinal cord synaptic plasticity and inflammatory pain with neuroprotectin D1. J Neurosci. 2011;31(42):15072-85.

51. Headland SE, Norling LV. The resolution of inflammation: principles and challenges. Semin Immunol. 2015;27(3):149-60.

52. Marcon R, Bento AF, Dutra RC, Bicca MA, Leite DF, Calixto JB. Maresin 1, a proresolving lipid mediator derived from omega-3 polyunsaturated fatty acids, exerts protective actions in murine models of colitis. J Immunol. 2013;191(8):4288-98.

53. Serhan CN, Yang R, Martinod K, et al. Maresins: novel macrophage mediators with potent antiinflammatory and proresolving actions. J Exp Med. 2009;206(1):15-23.

54. Abdulnour RE, Dalli J, Colby JK, et al. Maresin 1 biosynthesis during platelet-neutrophil interactions is organ-protective. Proc Natl Acad Sci U S A. 2014;111(46):16526-31.

55. Bratton DL, Henson PM. Neutrophil clearance: when the party is over clean-up begins. Trends Immunol. 2011;32(8):350-7.

56. El Kebir D, József L, Khreiss T, et al. Aspirin-triggered lipoxins override the apoptosis-delaying action of serum amyloid $A$ in human neutrophils: a novel mechanism for resolution of inflammation. J Immunol. 2007;179(1):616-22

57. El Kebir D, Filep JG. Targeting neutrophil apoptosis for enhancing the resolution of inflammation. Cells. 2013;2(2):330-48.

58. Vago JP, Nogueira $C R$, Tavares LP, et al. Annexin A1 modulates natural and glucocorticoid-induced resolution of inflammation by enhancing neutrophil apoptosis. J Leukoc Biol. 2012;92(2):249-58.

59. Rosales C. Neutrophil: a cell with many roles in inflammation or several cell types. Front Physiol. 2018;9:113.

60. El Kebir D, Gjorstrup P, Filep JG. Resolvin E1 promotes phagocytosisinduced neutrophil apoptosis and accelerates resolution of pulmonary inflammation. Proc Natl Acad Sci U S A. 2012;109(37):14983-8.

61. Sima C, Paster B, Van Dyke TE. Function of pro-resolving lipid mediator resolvin E1 in type 2 diabetes. Crit Rev Immunol. 2018;38(5):343-65.

62. Ji RR, Xu ZZ, Strichartz G, Serhan CN. Emerging roles of resolvins in the resolution of inflammation and pain. Trends Neurosci. 2011;34(11):599-609.

63. Brinkmann V, Reichard U, Goosmann C, et al. Neutrophil extracellular traps kill bacteria. Science. 2004:303(5663):1532-5.

64. Qi H, Yang S, Zhang L. Neutrophil extracellular traps and endothelial dysfunction in atherosclerosis and thrombosis. Front Immunol. 2017;8:928

65. Gisterå A, Hansson GK. The immunology of atherosclerosis. Nat Rev Nephrol. 2017;13(6):368-80.

66. Leppkes M, Schick M, Hohberger B, et al. Updates on NET formation in health and disease. Semin Arthritis Rheum. 2019;49(3S):S43-8.

67. Wright TK, Gibson PG, Simpson JL, McDonald VM, Wood LG, Baines KJ. Neutrophil extracellular traps are associated with inflammation in chronic airway disease. Respirology. 2016;21(3):467-75.

68. Lachowicz-Scroggins ME, Dunican EM, Charbit AR, et al. Extracellular DNA, neutrophil extracellular traps, and inflammasome activation in severe asthma. Am J Respir Crit Care Med. 2019;199(9):1076-85.

69. Grabcanovic-Musija F, Obermayer A, Stoiber W, et al. Neutrophil extracellular trap (NET) formation characterises stable and exacerbated COPD and correlates with airflow limitation. Respir Res. 2015;16:59.

70. Pedersen F, Marwitz S, Holz O, et al. Neutrophil extracellular trap formation and extracellular DNA in sputum of stable COPD patients. Respir Med. 2015:109(10):1360-2.

71. Arpinati L, Shaul ME, Kaisar-Iluz N, Mali S, Mahroum S, Fridlender ZG. NETosis in cancer: a critical analysis of the impact of cancer on neutrophil extracellular trap (NET) release in lung cancer patients vs mice. Cancer Immunol Immunother. 2020;69(2):199-213. 
72. Urban CF, Ermert D, Schmid M, et al. Neutrophil extracellular traps contain calprotectin, a cytosolic protein complex involved in host defense against Candida albicans. PLoS Pathog. 2009;5(10): e1000639.

73. Lefrançais E, Mallavia B, Zhuo H, Calfee CS, Looney MR. Maladaptive role of neutrophil extracellular traps in pathogen-induced lung injury. JCl Insight. 2018. https://doi.org/10.1172/jci.insight.98178.

74. Cherpokova D, Jouvene CC, Libreros S, DeRoo EP, Chu L, de la Rosa X, Norris PC, Wagner DD, Serhan CN. Resolvin D4 attenuates the severity of pathological thrombosis in mice. Blood. 2019;134:1458-68. https:// doi.org/10.1182/blood.2018886317.

75. Arandjelovic S, Ravichandran KS. Phagocytosis of apoptotic cells in homeostasis. Nat Immunol. 2015;16(9):907-17.

76. Grabiec AM, Hussell T. The role of airway macrophages in apoptotic cell clearance following acute and chronic lung inflammation. Semin Immunopathol. 2016;38(4):409-23.

77. Arienti S, Barth ND, Dorward DA, Rossi AG, Dransfield I. Regulation of apoptotic cell clearance during resolution of inflammation. Front Pharmacol. 2019;10:891.

78. Gordon S. Alternative activation of macrophages. Nat Rev Immunol. 2003;3(1):23-35.

79. Arora S, Dev K, Agarwal B, Das P, Syed MA. Macrophages: their role, activation and polarization in pulmonary diseases. Immunobiology. 2018;223(4-5):383-96.

80. Shapouri-Moghaddam A, Mohammadian S, Vazini H, et al. Macrophage plasticity, polarization, and function in health and disease. J Cell Physiol. 2018;233(9):6425-40.

81. Herová M, Schmid M, Gemperle C, Hersberger M. ChemR23, the receptor for chemerin and resolvin E1, is expressed and functional on $\mathrm{M} 1$ but not on M2 macrophages. J Immunol. 2015;194(5):2330-7.

82. Gordon S, Martinez FO. Alternative activation of macrophages: mechanism and functions. Immunity. 2010;32(5):593-604.

83. Gregory CD, Pound JD. Cell death in the neighbourhood: direct microenvironmental effects of apoptosis in normal and neoplastic tissues. J Pathol. 2011;223(2):177-94.

84. Salina AC, Souza TP, Serezani CH, Medeiros Al. Efferocytosis-induced prostaglandin E2 production impairs alveolar macrophage effector functions during Streptococcus pneumoniae infection. Innate Immun. 2017;23(3):219-27.

85. Kumar V. Pulmonary innate immune response determines the outcome of inflammation during pneumonia and sepsis-associated acute lung injury. Front Immunol. 2020;11:1722. https://doi.org/10.3389/fimmu. 2020.01722.

86. Zheng Y, Ning P, Luo Q, et al. Inflammatory responses relate to distinct bronchoalveolar lavage lipidome in community-acquired pneumonia patients: a pilot study. Respir Res. 2019;20(1):82.

87. Sun $X$, Song L, Feng S, et al. Fatty acid metabolism is associated with disease severity after H7N9 infection. EBioMedicine. 2018;33:218-29.

88. Schmidt R, Luboeinski T, Markart P, et al. Alveolar antioxidant status in patients with acute respiratory distress syndrome. Eur Respir J. 2004;24(6):994-9.

89. Dalli J, Kraft BD, Colas RA, et al. The regulation of proresolving lipid mediator profiles in baboon pneumonia by inhaled carbon monoxide. Am J Respir Cell Mol Biol. 2015;53(3):314-25.

90. Ruffin M, Brochiero E. Repair process impairment by Pseudomonas aeruginosa in epithelial tissues: major features and potential therapeutic avenues. Front Cell Infect Microbiol. 2019;9:182.

91. Abdulnour RE, Sham HP, Douda DN, et al. Aspirin-triggered resolvin D1 is produced during self-resolving gram-negative bacterial pneumonia and regulates host immune responses for the resolution of lung inflammation. Mucosal Immunol. 2016;9(5):1278-87.

92. Codagnone M, Cianci E, Lamolinara A, et al. Resolvin D1 enhances the resolution of lung inflammation caused by long-term Pseudomonas aeruginosa infection. Mucosal Immunol. 2018;11(1):35-49.

93. Wu B, Capilato J, Pham MP, et al. Lipoxin A4 augments host defense in sepsis and reduces Pseudomonas aeruginosa virulence through quorum sensing inhibition. FASEB J. 2016;30(6):2400-10.

94. Higgins G, Fustero Torre C, Tyrrell J, McNally P, Harvey BJ, Urbach V. Lipoxin A4 prevents tight junction disruption and delays the colonization of cystic fibrosis bronchial epithelial cells by Pseudomonas aeruginosa. Am J Physiol Lung Cell Mol Physiol. 2016;310(11):L1053-61.
95. Cilloniz C, Pantin-Jackwood MJ, Ni C, et al. Lethal dissemination of H5N1 influenza virus is associated with dysregulation of inflammation and lipoxin signaling in a mouse model of infection. J Virol. 2010;84(15):7613-24.

96. Morita M, Kuba K, Ichikawa A, et al. The lipid mediator protectin D1 inhibits influenza virus replication and improves severe influenza. Cell. 2013;153(1):112-25.

97. Ramon S, Baker SF, Sahler JM, et al. The specialized proresolving mediator 17-HDHA enhances the antibody-mediated immune response against influenza virus: a new class of adjuvant. J Immunol. 2014;193(12):6031-40.

98. Russell CD, Schwarze J. The role of pro-resolution lipid mediators in infectious disease. Immunology. 2014;141(2):166-73.

99. Furin J, Cox H, Pai M. Tuberculosis. Lancet. 2019;393(10181):1642.

100. Bussi C, Gutierrez MG. Mycobacterium tuberculosis infection of host cells in space and time. FEMS Microbiol Rev. 2019;43(4):341-61.

101. Ndlovu H, Marakalala MJ. Granulomas and inflammation: host-directed therapies for tuberculosis. Front Immunol. 2016;7:434.

102. Dorhoi A, Kaufmann SH. Pathology and immune reactivity: understanding multidimensionality in pulmonary tuberculosis. Semin Immunopathol. 2016;38(2):153-66.

103. Rendon JL, Li X, Akhtar S, Choudhry MA. Interleukin-22 modulates gut epithelial and immune barrier functions following acute alcohol exposure and burn injury. Shock. 2013;39(1):11-8.

104. Perusina Lanfranca M, Lin Y, Fang J, Zou W, Frankel T. Biological and pathological activities of interleukin-22. J Mol Med (Berl). 2016;94(5):523-34

105. Tripathi D, Radhakrishnan RK, Sivangala Thandi R, et al. IL-22 produced by type 3 innate lymphoid cells (ILC3s) reduces the mortality of type 2 diabetes mellitus (T2DM) mice infected with Mycobacterium tuberculosis. PLoS Pathog. 2019;15(12): e1008140.

106. Pedruzzi G, Das PN, Rao KV, Chatterjee S. Understanding PGE2, LXA4 and LTB4 balance during Mycobacterium tuberculosis infection through mathematical model. J Theor Biol. 2016;389:159-70.

107. Colas RA, Nhat L, Thuong N, et al. Proresolving mediator profiles in cerebrospinal fluid are linked with disease severity and outcome in adults with tuberculous meningitis. FASEB J. 2019;33(11):13028-39.

108. Pavan Kumar N, Moideen K, Nancy A, et al. Plasma eicosanoid levels in tuberculosis and tuberculosis-diabetes co-morbidity are associated with lung pathology and bacterial burden. Front Cell Infect Microbiol. 2019;9:335

109. Shivakoti R, Dalli J, Kadam D, et al. Lipid mediators of inflammation and resolution in individuals with tuberculosis and tuberculosis-diabetes. Prostaglandins Other Lipid Mediat. 2020;147:106398.

110. Arnett E, Weaver AM, Woodyard KC, et al. PPARY is critical for Mycobacterium tuberculosis induction of $\mathrm{MCl}-1$ and limitation of human macrophage apoptosis. PLoS Pathog. 2018;14(6): e1007100.

111. Guirado E, Rajaram MV, Chawla A, et al. Deletion of PPARy in lung macrophages provides an immunoprotective response against $\mathrm{M}$. tuberculosis infection in mice. Tuberculosis (Edinb). 2018;111:170-7.

112. Chen $M$, Divangahi $M, G a n ~ H$, et al. Lipid mediators in innate immunity against tuberculosis: opposing roles of PGE2 and LXA4 in the induction of macrophage death. J Exp Med. 2008;205(12):2791-801.

113. Nunes C, Pereira AM, Morais-Almeida M. Asthma costs and social impact. Asthma Res Pract. 2017;3:1.

114. Ishmael FT. The inflammatory response in the pathogenesis of asthma. J Am Osteopath Assoc. 2011;111:S11.

115. Barnig C, Cernadas M, Dutile S, et al. Lipoxin A4 regulates natural killer cell and type 2 innate lymphoid cell activation in asthma. Sci Transl Med. 2013:5(174):174ra26.

116. Kazani S, Planaguma A, Ono E, et al. Exhaled breath condensate eicosanoid levels associate with asthma and its severity. J Allergy Clin Immunol. 2013;132(3):547-53.

117. Oyesola OO, Duque C, Huang LC, Larson EM, Früh SP, Webb LM, et al. The prostaglandin D2 receptor CRTH2 promotes IL-33-induced ILC2 accumulation in the lung. J Immunol. 2020;204:1001-11. https://doi. org/10.4049/jimmunol.1900745.

118. Levy BD, Serhan CN. Resolution of acute inflammation in the lung. Annu Rev Physiol. 2014;76:467-92. 
119. Ariel A, Fredman G, Sun YP, et al. Apoptotic neutrophils and T cells sequester chemokines during immune response resolution through modulation of CCR5 expression. Nat Immunol. 2006;7(11):1209-16.

120. Haworth $\mathrm{O}$, Cernadas M, Levy BD. NK cells are effectors for resolvin E1 in the timely resolution of allergic airway inflammation. J Immunol. 2011;186(11):6129-35.

121. Duvall MG, Krishnamoorthy N, Levy BD. Non-type 2 inflammation in severe asthma is propelled by neutrophil cytoplasts and maintained by defective resolution. Allergol Int. 2019;68:143-9. https://doi.org/10. 1016/j.alit.2018.11.006.

122. Hatchwell L, Collison A, Girkin J, et al. Toll-like receptor 7 governs interferon and inflammatory responses to rhinovirus and is suppressed by IL-5-induced lung eosinophilia. Thorax. 2015;70(9):854-61.

123. Kilburg-Basnyat B, Reece SW, Crouch MJ, et al. Specialized pro-resolving lipid mediators regulate ozone-induced pulmonary and systemic inflammation. Toxicol Sci. 2018;163(2):466-77.

124. Ono E, Dutile $S$, Kazani $S$, et al. Lipoxin generation is related to soluble epoxide hydrolase activity in severe asthma. Am J Respir Crit Care Med. 2014;190(8):886-97.

125. Grumbach Y, Quynh NV, Chiron R, Urbach V. LXA4 stimulates ZO-1 expression and transepithelial electrical resistance in human airway epithelial (16HBE140-) cells. Am J Physiol Lung Cell Mol Physiol. 2009;296(1):L101-8.

126. Perretti M, D'Acquisto F. Annexin A1 and glucocorticoids as effectors of the resolution of inflammation. Nat Rev Immunol. 2009;9(1):62-70.

127. Vachier I, Bonnans C, Chavis C, et al. Severe asthma is associated with a loss of LX4, an endogenous anti-inflammatory compound. J Allergy Clin Immunol. 2005;115(1):55-60.

128. Charriot J, Vachier I, Halimi L, et al. Future treatment for asthma. Eur Respir Rev. 2016;25(139):77-92.

129. Chan S, Selemidis S, Bozinovski S, Vlahos R. Pathobiological mechanisms underlying metabolic syndrome (MetS) in chronic obstructive pulmonary disease (COPD): clinical significance and therapeutic strategies. Pharmacol Ther. 2019;198:160-88.

130. Barnes PJ. Cellular and molecular mechanisms of chronic obstructive pulmonary disease. Clin Chest Med. 2014;35(1):71-86.

131. Kim KH, ParkTS, Kim YS, et al. Resolvin D1 prevents smoking-induced emphysema and promotes lung tissue regeneration. Int J Chron Obstruct Pulmon Dis. 2016;11:1119-28.

132. Croasdell A, Thatcher TH, Kottmann RM, et al. Resolvins attenuate inflammation and promote resolution in cigarette smokeexposed human macrophages. Am J Physiol Lung Cell Mol Physiol. 2015;309(8):L888-901.

133. Balode L, Strazda G, Jurka N, et al. Lipoxygenase-derived arachidonic acid metabolites in chronic obstructive pulmonary disease. Medicina (Kaunas). 2012:48(6):292-8.

134. Pena KB, Ramos CO, Soares NP, et al. The administration of a high refined carbohydrate diet promoted an increase in pulmonary inflammation and oxidative stress in mice exposed to cigarette smoke. Int J Chron Obstruct Pulmon Dis. 2016;11:3207-17.

135. Tontonoz P, Spiegelman BM. Fat and beyond: the diverse biology of PPARgamma. Annu Rev Biochem. 2008;77:289-312.

136. Lakshmi SP, Reddy AT, Zhang Y, et al. Down-regulated peroxisome proliferator-activated receptor $\gamma$ (PPAR $\gamma$ ) in lung epithelial cells promotes a PPARy agonist-reversible proinflammatory phenotype in chronic obstructive pulmonary disease (COPD). J Biol Chem. 2014:289(10):6383-93.

137. Hong C, Tontonoz P. Liver $X$ receptors in lipid metabolism: opportunities for drug discovery. Nat Rev Drug Discov. 2014;13(6):433-44.

138. Shimano H, Sato R. SREBP-regulated lipid metabolism: convergent physiology - divergent pathophysiology. Nat Rev Endocrinol. 2017:13(12):710-30

139. DeBose-Boyd RA, Ye J. SREBPs in lipid metabolism, insulin signaling, and beyond. Trends Biochem Sci. 2018;43(5):358-68.

140. Shan M, You R, Yuan X, et al. Agonistic induction of PPARY reverses cigarette smoke-induced emphysema. J Clin Invest. 2014;124(3):1371-81.

141. Solleti SK, Simon DM, Srisuma S, et al. Airway epithelial cell PPARY modulates cigarette smoke-induced chemokine expression and emphysema susceptibility in mice. Am J Physiol Lung Cell Mol Physiol. 2015;309(3):L293-304
142. Lea S, Plumb J, Metcalfe H, et al. The effect of peroxisome proliferatoractivated receptor- $\gamma$ ligands on in vitro and in vivo models of COPD. Eur Respir J. 2014:43(2):409-20.

143. Morissette MC, Shen P, Thayaparan D, Stämpfli MR. Impacts of peroxisome proliferator-activated receptor- $\gamma$ activation on cigarette smoke-induced exacerbated response to bacteria. Eur Respir J. 2015;45(1):191-200.

144. Grzela K, Litwiniuk M, Zagorska W, Grzela T. Airway remodeling in chronic obstructive pulmonary disease and asthma: the role of matrix metalloproteinase-9. Arch Immunol Ther Exp (Warsz). 2016;64(1):47-55.

145. Yang DC, Chen $\mathrm{CH}$. Cigarette smoking-mediated macrophage reprogramming: mechanistic insights and therapeutic implications. J Nat Sci. 2018;4(11):e539.

146. Yuan F, Fu X, Shi H, Chen G, Dong P, Zhang W. Induction of murine macrophage $M 2$ polarization by cigarette smoke extract via the JAK2/STAT3 pathway. PLoS ONE. 2014;9(9): e107063.

147. Takamiya R, Fukunaga K, Arita M, et al. Resolvin E1 maintains macrophage function under cigarette smoke-induced oxidative stress. FEBS Open Bio. 2012:2:328-33.

148. Hsiao HM, Sapinoro RE, Thatcher TH, et al. A novel anti-inflammatory and pro-resolving role for resolvin D1 in acute cigarette smokeinduced lung inflammation. PLoS ONE. 2013;8(3): e58258.

149. Han S, Mallampalli RK. The acute respiratory distress syndrome: from mechanism to translation. J Immunol. 2015;194(3):855-60.

150. Zarbock A, Singbartl K, Ley K. Complete reversal of acid-induced acute lung injury by blocking of platelet-neutrophil aggregation. J Clin Invest. 2006;116(12):3211-9.

151. Eickmeier $\mathrm{O}$, Seki $\mathrm{H}$, Haworth $\mathrm{O}$, et al. Aspirin-triggered resolvin D1 reduces mucosal inflammation and promotes resolution in a murine model of acute lung injury. Mucosal Immunol. 2013;6(2):256-66.

152. Colby JK, Abdulnour RE, Sham HP, et al. Resolvin D3 and aspirintriggered resolvin D3 are protective for injured epithelia. Am J Pathol. 2016;186(7):1801-13.

153. Schmid M, Gemperle C, Rimann N, Hersberger M. Resolvin D1 polarizes primary human macrophages toward a proresolution phenotype through GPR32. J Immunol. 2016;196(8):3429-37.

154. Qi W, Li H, Cai XH, et al. Lipoxin A4 activates alveolar epithelial sodium channel gamma via the microRNA-21/PTEN/AKT pathway in lipopolysaccharide-induced inflammatory lung injury. Lab Invest. 2015;95(11):1258-68.

155. Czerska K, Sobczynska-Tomaszewska A, Sands D, et al. Prostaglandinendoperoxide synthase genes COX1 and COX2 - novel modifiers of disease severity in cystic fibrosis patients. J Appl Genet. 2010;51(3):323-30.

156. Yang J, Eiserich JP, Cross CE, Morrissey BM, Hammock BD. Metabolomic profiling of regulatory lipid mediators in sputum from adult cystic fibrosis patients. Free Radic Biol Med. 2012;53(1):160-71.

157. Iuliano L, Monticolo R, Straface G, et al. Association of cholesterol oxidation and abnormalities in fatty acid metabolism in cystic fibrosis. Am J Clin Nutr. 2009:90(3):477-84

158. Eickmeier O, Fussbroich D, Mueller K, et al. Pro-resolving lipid mediator Resolvin D1 serves as a marker of lung disease in cystic fibrosis. PLoS ONE. 2017;12(2): e0171249.

159. Hvorecny KL, Dolben E, Moreau-Marquis S, et al. An epoxide hydrolase secreted by Pseudomonas aeruginosa decreases mucociliary transport and hinders bacterial clearance from the lung. Am J Physiol Lung Cell Mol Physiol. 2018;314(1):L150-6.

160. Flitter BA, Hvorecny KL, Ono E, et al. Pseudomonas aeruginosa sabotages the generation of host proresolving lipid mediators. Proc Natl Acad Sci U S A. 2017;114(1):136-41.

161. Zhong Y, Catheline D, Houeijeh A, et al. Maternal omega-3 PUFA supplementation prevents hyperoxia-induced pulmonary hypertension in the offspring. Am J Physiol Lung Cell Mol Physiol. 2018;315(1):L116-32.

162. Sharma D, Nkembi AS, Aubry E, et al. Maternal PUFA $\omega-3$ supplementation prevents neonatal lung injuries induced by hyperoxia in newborn rats. Int J Mol Sci. 2015;16(9):22081-93.

163. Martin CR, Zaman MM, Gilkey C, et al. Resolvin D1 and lipoxin A4 improve alveolarization and normalize septal wall thickness in a neonatal murine model of hyperoxia-induced lung injury. PLOS ONE. 2014;9(6): e98773. 
164. Elliott E, Hanson CK, Anderson-Berry AL, Nordgren TM. The role of specialized pro-resolving mediators in maternal-fetal health. Prostaglandins Leukot Essent Fatty Acids. 2017;126:98-104.

165. Morty RE, Königshoff M, Eickelberg O. Transforming growth factor-beta signaling across ages: from distorted lung development to chronic obstructive pulmonary disease. Proc Am Thorac Soc. 2009;6(7):607-13.

166. Alejandre-Alcázar MA, Kwapiszewska G, Reiss I, et al. Hyperoxia modulates TGF-beta/BMP signaling in a mouse model of bronchopulmonary dysplasia. Am J Physiol Lung Cell Mol Physiol. 2007;292(2):L537-49.

167. Lignelli E, Palumbo F, Myti D, Morty RE. Recent advances in our understanding of the mechanisms of lung alveolarization and bronchopulmonary dysplasia. Am J Physiol Lung Cell Mol Physiol. 2019;317(6):L832-87.

168. Chen XQ, Wu SH, Luo YY, et al. Lipoxin A4 attenuates bronchopulmonary dysplasia via upregulation of Let-7c and downregulation of TGF- $\beta 1$ signaling pathway. Inflammation. 2017:40(6):2094-108.

169. Ji YD, Luo ZL, Chen CX, et al. BML-111 suppresses TGF- $\beta 1$-induced lung fibroblast activation in vitro and decreases experimental pulmonary fibrosis in vivo. Int J Mol Med. 2018;42(6):3083-92.

170. Kindermann A, Binder L, Baier J, et al. Severe but not moderate hyperoxia of newborn mice causes an emphysematous lung phenotype in adulthood without persisting oxidative stress and inflammation. BMC Pulm Med. 2019;19(1):245.

171. Vandenbroucke RE, Dejonckheere E, Libert C. A therapeutic role for matrix metalloproteinase inhibitors in lung diseases. Eur Respir J. 2011;38(5):1200-14

172. Wątroba S, Kocot J, Bryda J, Kurzepa J. Serum activity of MMP-2 and MMP-9 and stromielisin-1 concentration as predictors in the pathogenesis of bronchopulmonary dysplasia in preterm neonates. Postępy Higieny i Medycyny Doświadczalnej. 2019;73:703.

173. Li G, Fan Y, Lai Y, et al. Coronavirus infections and immune responses. J Med Virol. 2020;92(4):424-32.

174. Rogero MM, Leão MC, Santana TM, Pimentel M, Carlini G, da Silveira T, Gonçalves RC, Castro IA. Potential benefits and risks of omega-3 fatty acids supplementation to patients with COVID-19. Free Radic Biol Med. 2020;156:190-9. https://doi.org/10.1016/j.freeradbiomed.2020.07.005.

175. Panigrahy D, Gilligan MM, Huang S, Gartung A, Cortés-Puch I, Sime PJ, Phipps RP, Serhan CN, Hammock BD. Inflammation resolution: a dual-pronged approach to averting cytokine storms in COVID-19. Cancer Metastasis Rev. 2020;39:337-40. https://doi.org/10.1007/ s10555-020-09889-4.

176. Ren Y, Yao MC, Huo XQ, Gu Y, Zhu WX, Qiao YJ, Zhang YL. Study on treatment of "cytokine storm" by anti-2019-nCoV prescriptions based on arachidonic acid metabolic pathway. Zhongguo Zhong Yao Za Zhi. 2020;45:1225-31. https://doi.org/10.19540/j.cnki.cjcmm.20200224.405.

177. Maderna P, Cottell DC, Toivonen T, et al. FPR2/ALX receptor expression and internalization are critical for lipoxin A4 and annexin-derived peptide-stimulated phagocytosis. FASEB J. 2010;24(11):4240-9. https:// doi.org/10.1096/fj.10-159913.

178. Prieto P, Cuenca J, Través PG, Fernández-Velasco M, Martín-Sanz P, Boscá L. Lipoxin A4 impairment of apoptotic signaling in macrophages: implication of the PI3K/Akt and the ERK/Nrf-2 defense pathways. Cell Death Differ. 2010;17:1179-88. https://doi.org/10.1038/cdd.2009.220.

179. Chen QF, Kuang XD, Yuan QF, Hao H, Zhang T, Huang YH, et al. Lipoxin A4 attenuates LPS-induced acute lung injury via activation of the ACE2Ang-(1-7)-Mas axis. Innate Immun. 2018;24:285-96. https://doi.org/10. $1177 / 1753425918785008$.

180. Zheng S, D'Souza VK, Bartis D, Dancer RC, Parekh D, Naidu B, et al. Lipoxin A4 promotes lung epithelial repair whilst inhibiting fibroblast proliferation. ERJ Open Res. 2016. https://doi.org/10.1183/23120541. 00079-2015.

181. Karra L, Haworth O, Priluck R, Levy BD, Levi-Schaffer F. Lipoxin B $B_{4}$ promotes the resolution of allergic inflammation in the upper and lower airways of mice. Mucosal Immunol. 2015;8:852-62. https://doi.org/10. 1038/mi.2014.116.

182. Dalli J, Serhan CN. Specific lipid mediator signatures of human phagocytes: microparticles stimulate macrophage efferocytosis and pro-resolving mediators. Blood. 2012;120:e60-72. https://doi.org/10. 1182/blood-2012-04-423525.

183. Chiang N, Fierro IM, Gronert K, Serhan CN. Activation of lipoxin A(4) receptors by aspirin-triggered lipoxins and select peptides evokes ligand-specific responses in inflammation. J Exp Med. 2000;191:1197208. https://doi.org/10.1084/jem.191.7.1197.

184. Wang Q, Yan SF, Hao Y, Jin SW. Specialized pro-resolving mediators regulate alveolar fluid clearance during acute respiratory distress syndrome. Chin Med J (Engl). 2018;131:982-9. https://doi.org/10.4103/ 0366-6999.229890.

185. Laguna-Fernandez A, Checa A, Carracedo M, Artiach G, Petri MH, Baumgartner R, et al. ERV1/ChemR23 signaling protects against atherosclerosis by modifying oxidized low-density lipoprotein uptake and phagocytosis in macrophages. Circulation. 2018;138:1693-705. https:// doi.org/10.1161/CIRCULATIONAHA. 117.032801.

186. Rajendran M, Maria NT. Resolvins, a powerful resolution mediator: review. Int J Appl Dent Sci. 2015;1(5):13.

187. Oh SF, Dona M, Fredman G, Krishnamoorthy S, Irimia D, Serhan CN. Resolvin E2 formation and impact in inflammation resolution. J Immunol. 2012;188:4527-34. https://doi.org/10.4049/jimmunol.1103652.

188. Chattopadhyay R, Raghavan S, Rao GN. Resolvin D1 via prevention of ROS-mediated SHP2 inactivation protects endothelial adherens junction integrity and barrier function. Redox Biol. 2017;12:438-55. https:// doi.org/10.1016/j.redox.2017.02.023.

189. Krishnamoorthy $S$, Recchiuti $A$, Chiang $N$, et al. Resolvin D1 binds human phagocytes with evidence for proresolving receptors. Proc Natl Acad Sci U S A. 2010;107(4):1660-5. https://doi.org/10.1073/pnas.09073 42107.

190. Chiang N, de la Rosa X, Libreros S, et al. Novel resolvin D2 receptor axis in infectious inflammation. J Immunol. 2017;198(2):842-51. https://doi. org/10.4049/jimmunol.1601650.

191. Gallo J, Raska M, Kriegova E, Goodman SB. Inflammation and its resolution and the musculoskeletal system. J Orthop Translat. 2017;10:52-67.

192. Li Y, Chen S, Chi Y, Yang Y, Chen X, Wang H, et al. Kinetics of the accumulation of group 2 innate lymphoid cells in IL-33-induced and IL-25-induced murine models of asthma: a potential role for the chemokine CXCL16. Cell Mol Immunol. 2019;16:75-86. https://doi.org/ 10.1038/s41423-018-0182-0.

193. Polito AJ, Proud D. Epithelial cells as regulators of airway inflammation. J Allergy Clin Immunol. 1998;102(5):714.

194. Wu SH, Zhang YM, Tao HX, Dong L. Lipoxin A(4) inhibits transition of epithelial to mesenchymal cells in proximal tubules. Am J Nephrol. 2010;32:122-36. https://doi.org/10.1159/000315121.

\section{Publisher's Note}

Springer Nature remains neutral with regard to jurisdictional claims in published maps and institutional affiliations. 